\title{
Tailoring stress in pyrolytic carbon for fabrication of nanomechanical string
} resonators

\author{
Quang, Long Nguyen; Larsen, Peter Emil; Boisen, Anja; Keller, Stephan Sylvest
}

Published in:

Carbon

Link to article, DOI:

10.1016/j.carbon.2018.03.005

Publication date:

2018

Document Version

Peer reviewed version

Link back to DTU Orbit

Citation (APA):

Quang, L. N., Larsen, P. E., Boisen, A., \& Keller, S. S. (2018). Tailoring stress in pyrolytic carbon for fabrication of nanomechanical string resonators. Carbon, 133, 358-368. https://doi.org/10.1016/j.carbon.2018.03.005

\section{General rights}

Copyright and moral rights for the publications made accessible in the public portal are retained by the authors and/or other copyright owners and it is a condition of accessing publications that users recognise and abide by the legal requirements associated with these rights.

- Users may download and print one copy of any publication from the public portal for the purpose of private study or research.

- You may not further distribute the material or use it for any profit-making activity or commercial gain

- You may freely distribute the URL identifying the publication in the public portal

If you believe that this document breaches copyright please contact us providing details, and we will remove access to the work immediately and investigate your claim 


\section{Accepted Manuscript}

Tailoring stress in pyrolytic carbon for fabrication of nanomechanical string resonators

Long Nguyen Quang, Peter Emil Larsen, Anja Boisen, Stephan Sylvest Keller

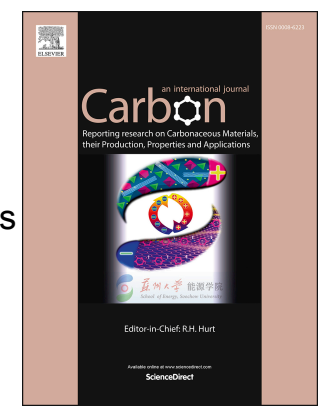

PII: S0008-6223(18)30248-3

DOI: $\quad$ 10.1016/j.carbon.2018.03.005

Reference: CARBON 12948

To appear in: Carbon

Received Date: 5 January 2018

Revised Date: 2 March 2018

Accepted Date: 3 March 2018

Please cite this article as: L.N. Quang, P.E. Larsen, A. Boisen, S.S. Keller, Tailoring stress in pyrolytic carbon for fabrication of nanomechanical string resonators, Carbon (2018), doi: 10.1016/ j.carbon.2018.03.005.

This is a PDF file of an unedited manuscript that has been accepted for publication. As a service to our customers we are providing this early version of the manuscript. The manuscript will undergo copyediting, typesetting, and review of the resulting proof before it is published in its final form. Please note that during the production process errors may be discovered which could affect the content, and all legal disclaimers that apply to the journal pertain. 


\title{
Tailoring stress in pyrolytic carbon for fabrication of nanomechanical string resonators
}

Long Nguyen Quang ${ }^{1,2}$, Peter Emil Larsen ${ }^{1,2}$, Anja Boisen ${ }^{1,2}$ and Stephan Sylvest Keller 1, 2, *

1 Department of Micro- and Nanotechnology, Technical University of Denmark, $2800 \mathrm{Kgs}$. Lyngby, Denmark

2 DNRF and Villum Fonden Center for Intelligent Drug Delivery and Sensing Using Microcontainers and Nanomechanics, IDUN, Technical University of Denmark, 2800 Kgs. Lyngby, Denmark

*Corresponding author. Tel: +45 45255846. Email: Stephan.Keller@ nanotech.dtu.dk

\begin{abstract}
In order to achieve high resonance frequencies and quality factors of pyrolytic carbon MEMS string resonators the resonator material needs to have a large tensile stress. In this study, the influence of pyrolysis temperature, dwell time and ramping rate on the residual stress in thin pyrolytic carbon films is investigated with the bending plate method. The results show that the pyrolysis temperature is the most important parameter for tailoring the residual stress, with a transition from tensile stress at temperature below $800^{\circ} \mathrm{C}$ to compressive stress at temperatures above $800^{\circ} \mathrm{C}$. Two kinds of photoresist: positive (AZ5214E) and negative (SU-8) and different pyrolysis conditions are used to fabricate pyrolytic carbon string resonators at variable pyrolysis conditions. The best performance is obtained for devices with a length of $400 \mu \mathrm{m}$ fabricated at a pyrolysis temperature of $700^{\circ} \mathrm{C}$, ramping rate of $30^{\circ} \mathrm{C} / \mathrm{min}$ and 10 minutes dwell time corresponding to the conditions for maximum tensile stress in pyrolytic carbon thin films. The optimized pyrolytic carbon string resonators had resonant frequencies above $300 \mathrm{kHz}$ and quality factors $(Q)$ in the order of $10^{4}$, which is suitable for their application as nanomechanical sensors.
\end{abstract}


ACCEPTED MANUSCRIPT
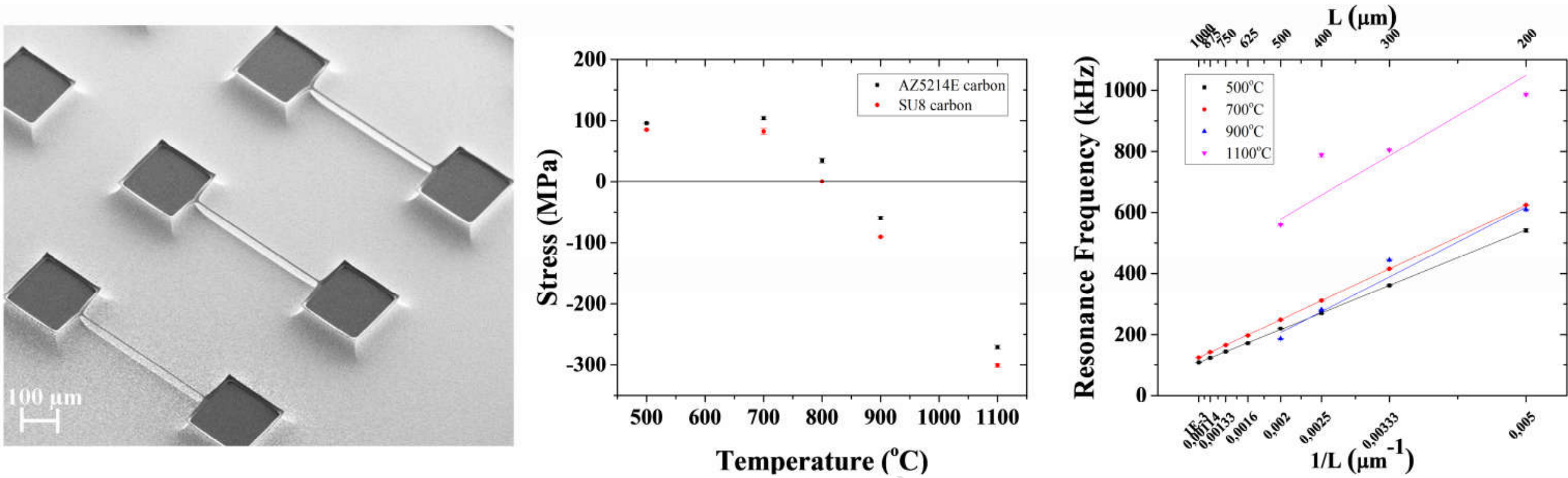


\title{
Tailoring stress in pyrolytic carbon for fabrication of nanomechanical string resonators
}

Long Nguyen Quang ${ }^{1,2}$, Peter Emil Larsen ${ }^{1,2}$, Anja Boisen ${ }^{1,2}$ and Stephan Sylvest Keller 1, 2,*

1 Department of Micro- and Nanotechnology, Technical University of Denmark, $2800 \mathrm{Kgs}$. Lyngby, Denmark

2 DNRF and Villum Fonden Center for Intelligent Drug Delivery and Sensing Using Microcontainers and Nanomechanics, IDUN, Technical University of Denmark, 2800 Kgs. Lyngby,

Denmark

*Corresponding author. Tel: +45 45255846. Email: Stephan.Keller@ nanotech.dtu.dk

\begin{abstract}
In order to achieve high resonance frequencies and quality factors of pyrolytic carbon MEMS string resonators the resonator material needs to have a large tensile stress. In this study, the influence of pyrolysis temperature, dwell time and ramping rate on the residual stress in thin pyrolytic carbon films is investigated with the bending plate method. The results show that the pyrolysis temperature is the most important parameter for tailoring the residual stress, with a transition from tensile stress at temperature below $800^{\circ} \mathrm{C}$ to compressive stress at temperatures above $800^{\circ} \mathrm{C}$. Two kinds of photoresist: positive (AZ5214E) and negative (SU-8) and different pyrolysis conditions are used to fabricate pyrolytic carbon string resonators at variable pyrolysis conditions. The best performance is obtained for devices with a length of $400 \mu \mathrm{m}$ fabricated at a pyrolysis temperature of $700^{\circ} \mathrm{C}$, ramping rate of $30^{\circ} \mathrm{C} / \mathrm{min}$ and 10 minutes dwell time corresponding to the conditions for maximum tensile stress in pyrolytic carbon thin films. The optimized pyrolytic carbon string resonators had resonant frequencies above $300 \mathrm{kHz}$ and quality factors $(Q)$ in the order of $10^{4}$, which is suitable for their application as nanomechanical sensors.
\end{abstract}

\section{Introduction}

Micro Electro-Mechanical Systems (MEMS) sensors are attractive for a wide range of applications such as pressure sensors, gyroscopes and accelerometers due to generally high sensitivity, small size and low fabrication costs. MEMS resonators such as cantilevers (single-clamped beams), strings (pre-stressed doubly-clamped beams) and membranes are commonly used in mass and force sensing because these devices exhibit a high sensitivity and short response time [1]. The working 
principle for MEMS resonators is based on a shift of the resonance frequency due to external stimuli such as changes in mass or temperature.

A significant amount of research has been performed on fabrication of MEMS resonators using e.g. SiN [2], SU-8 [3], and carbon-based materials [4-6]. Carbon-based materials such as silicon carbide, graphene and carbon-nanotubes (CNTs) show promising mechanical properties [7-9]. However, devices made of these materials are expensive and complicated to fabricate. Recently, a method for the fabrication of pyrolytic carbon micromechanical resonators has been proposed using a simple three step process [10]. First, photoresist-based microstructures are patterned by photolithography. Next, an isotropic etching of an underlying silicon substrate is performed. Finally, the suspended photoresist structures are converted into carbon resonators using a pyrolysis process at high temperature in an inert atmosphere [10]. A main advantage of pyrolytic carbon as a material for resonators is that its properties can be tailored by modifying the pyrolysis parameters [11]. Furthermore, pyrolytic carbon is a conductive material which can be useful for both integrated actuation and detection.

To achieve high sensitivity in sensing applications it is desirable to provide mechanical resonators with a high resonance frequency. For a double-clamped beam resonator under an axial load, the eigenfrequency $f_{n}$ of the $n_{\text {th }}$ resonance mode is given as [1]:

$$
f_{n}=\frac{(n \pi)^{2}}{2 \pi L^{2}} \sqrt{\frac{E I}{\rho A}} \sqrt{1+\frac{T L^{2}}{(n \pi)^{2} E I}}
$$

Where $L, A$ and $I$ are the length, cross-sectional area and moment of inertia of the beam, respectively. $E$ is the Young's modulus, $\rho$ is the density of the beam material and $T$ is the load. When the axial load is tensile $(T>0)$ and $T L^{2} /(n \pi)^{2} E I>>1$, the double-clamped beam is a string resonator and equation (1) becomes:

$$
f_{n}=\frac{n}{2 L} \sqrt{\frac{\sigma}{\rho}}
$$

Where $\sigma=T / A$ is the tensile stress. As described in equation (2), the resonance frequency for string resonators increases for higher tensile stress in the material which allows to achieve higher sensitivity and improved mechanical stability in sensing applications [13]. 
Another important figure of merit for string resonators is the quality factor ( $Q$ factor) which can be defined as the ratio of stored energy and lost energy during one cycle of vibration. The higher the $Q$ factor, the easier it is to monitor changes of the resonance frequency which again corresponds to a higher sensitivity of the string resonators for sensing applications. The $Q$ factor of the string resonator is the sum of several contributions as shown in equation (3) [12]:

$$
\frac{1}{Q}=\frac{1}{Q_{\text {medium }}}+\frac{1}{Q_{\text {clamping }}}+\frac{1}{Q_{\text {intrinsic }}}+\frac{1}{Q_{\text {other }}}
$$

Where $Q_{\text {medium }}$ is due to the losses caused by the interaction of the mechanical structure with a fluidic medium (gas or liquid), $Q_{\text {clamping }}$ is attributed to the losses of energy radiating into the environment at the physical clamping site of the string and $Q_{\text {intrinsic }}$ is related to the material properties of the resonators. Finally, $Q_{\text {other }}$ are all the damping mechanisms which are not included in the other contributions such as electrical charge damping or magnetomotive damping [12]. It is expected that the material properties, and thereby $Q_{\text {intrinsic, }}$ are highly dependent on the pyrolysis conditions used during the fabrication of the pyrolytic carbon string resonators.

Here, we present the optimization of the fabrication process to obtain pyrolytic carbon string resonators with high tensile stress and high $Q$ factors. To date no systematic study of the residual stress generated in pyrolytic carbon films during pyrolysis of photoresist layers has been published. Therefore, we systematically investigate the influence of temperature, ramping rate and dwell time on the residual stress in unpatterned thin carbon films obtained by pyrolysis of positive (AZ5214E) and negative (SU-8) photoresist using the bending plate method. These two photoresists were selected because they are commonly used in MEMS technology, have earlier shown promising properties after pyrolysis [14] and allow to evaluate the difference between positive and negative photoresist as the precursor materials for the pyrolysis process. In parallel, we fabricate carbon string resonators and compare the resonant behavior by measuring the resonance frequency and quality factors of devices with various dimensions. Finally, the aging of the pyrolytic carbon string resonators is investigated.

\section{Materials and Method}

\subsection{Fabrication process}

The fabrication process for the pyrolytic carbon string resonators is shown in Figure 1 and is similar to the method described earlier [10]. Briefly, photoresist strings were patterned on single side 
polished (ssp) 4-inch Si wafers by UV photolithography, followed by isotropic silicon etching. Finally, the photoresist string resonators were converted into pyrolytic carbon by pyrolysis. In this work, both positive and negative photoresist (AZ5214E and SU-8) were used for fabrication of the strings. The AZ5214E photoresist was spin coated on a Süss MicroTec Gamma 2M spin coater to obtain a thickness of $4 \mu \mathrm{m}$. The thickness of the SU-8 device layer was $6 \mu \mathrm{m}$ using a Süss MicroTec RCD8 T spin coater. The UV exposure was done on a Süss MicroTec MA6/BA6 aligner with a dose of $100 \mathrm{~mJ} / \mathrm{cm}^{2}$ for AZ5214E and $200 \mathrm{~mJ} / \mathrm{cm}^{2}$ for SU-8, respectively. For AZ5214E, the lithography step was concluded by developing the patterned structures using a Süss MicroTec Gamma 2M developer with TMAH solution for 90 s. For SU-8 photoresist, the development was performed with PGMEA for a total of 4 minutes. After development, an additional hard-bake for 1 hour at $120^{\circ} \mathrm{C}$ was introduced for both AZ5214E and SU-8 to improve the stability of the structures and avoid damage during the following etching process. The isotropic dry etching of $\mathrm{Si}$ was performed using a reactive etch with $\mathrm{SF}_{6}$ as the reactive gas in a STS MESC Multiplex ICP Advanced Silicon Etcher. The etching step was optimized to improve the structural definition of the released photoresist beams and maximize the fabrication yield by modifying the etch time, power and temperature. The optimized parameters for isotropic etching were $1500 \mathrm{~W}$ coil power, $0 \mathrm{~W}$ platen power, etch temperature $-10^{\circ} \mathrm{C}$ and etch time 10 minutes. With these etching parameters a fabrication yield of $98 \%$ was achieved for $15 \mu \mathrm{m}$ wide string resonators with a length of up to 750 $\mu \mathrm{m}$. In order to have high yields for string structures with smaller or larger widths, the etching time can be decreased or increased, respectively.

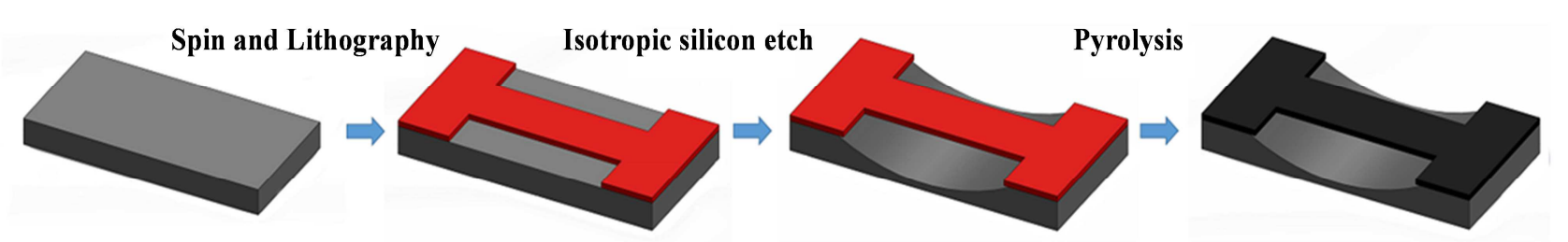

Figure 1: Fabrication process for the pyrolytic carbon string resonators.

2.2 Optimization of the pyrolysis process

For pyrolysis, a two-step thermal process was conducted in a PEO-604 furnace (ATV Technology, Germany). First, the samples were pre-conditioned at $200^{\circ} \mathrm{C}$ for $30 \mathrm{~min}$ followed by a second temperature step at the final pyrolysis temperature (Figure 2). The aim of the pyrolysis optimization was to maximize the tensile stress in the string resonators. The optimization of the pyrolysis process was performed by investigating the influence of three parameters in heating step 2: maximum 
temperature $T_{2}$, ramping rate $v_{2}$ and dwell time $t_{2}$. The maximum temperature was varied from $500^{\circ} \mathrm{C}$ to $1100^{\circ} \mathrm{C}$, the ramping rate between $2^{\circ} \mathrm{C} / \mathrm{min}$ and $30^{\circ} \mathrm{C} / \mathrm{min}$ and the dwelling time from 10 $\min$ to $600 \mathrm{~min}$.

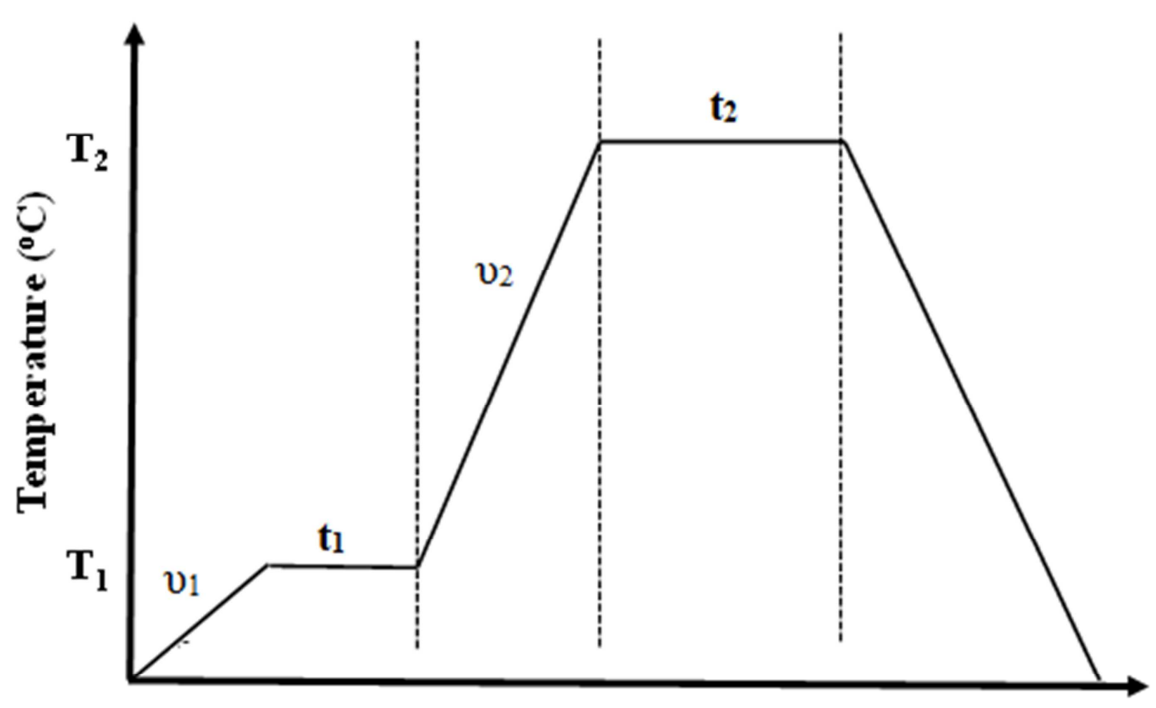

Time (min)

Figure 2: Temperature profile for a typical pyrolysis process.

\subsection{Thin film stress measurement}

In order to characterize the stress generated during pyrolysis, samples with unpatterned thin pyrolytic carbon films were prepared. AZ5214E and SU-8 films with a thickness of $4 \mu \mathrm{m}$ and $6 \mu \mathrm{m}$, respectively, were spin coated on 4-inch Si wafers. The films were processed with identical steps and parameters as described above for the pyrolytic carbon strings except that the dry etching step was omitted. The stress in the carbon thin films was determined using the bending plate method [15, 16]. For this purpose, the curvature of the substrate was measured prior to deposition of the photoresist and again along the same trace after completed processing of the film using a Dektak stylus profiler (DektakXTA). The stress in the deposited thin films was calculated based on the change in curvature assuming an initially flat substrate as:

$$
\sigma=\frac{1}{6}\left(\frac{1}{R_{p o s t}}-\frac{1}{R_{p r e}}\right) \frac{E}{(1-v)} \frac{t_{s}^{2}}{t_{f}}
$$

Where $\sigma$ is the stress in the film after deposition, $R_{\text {pre }}$ and $R_{\text {post }}$ are the substrate radii of curvature before and after deposition, $E$ is the Young's modulus of the substrate, $v$ is the Poisson's ratio of the 
substrate, and $t_{s}$ and $t_{f}$ are the thickness of the substrate and film, respectively. The film thickness was measured with a stylus profilometer on scratches made with a scalpel. Shrinkage was determine by characterizing the thickness of the thin film before and after pyrolysis. The percentage shrinkage can be expressed as [17]:

$$
s=\left(1-\frac{t_{c}}{t_{S U 8}}\right) \times 100
$$

Where $t_{S U 8}$ is the thickness of SU-8 layer before pyrolysis and $t_{C}$ is the thickness of carbon layer after pyrolysis. From those measured values, the stress was calculated by equation (4). Negative values are equal to compressive stress and positive values correspond to tensile stress. Raman spectra of the thin films were obtained by a Raman microscope from Thermo Scientific ${ }^{\mathrm{TM}} \mathrm{DXR}^{\mathrm{TM}}$ for determining the structure of the pyrolytic carbon.

\subsection{String resonator characterization}

After fabrication, the resonant behavior of the pyrolytic carbon strings was measured by the setup which is schematically shown in Figure 3. The pyrolytic carbon strings were placed on top of a piezoelectric crystal for actuation. The chip and the crystal were then placed in a vacuum chamber which was pumped down to below $10^{-5}$ mbar by means of a membrane pump and a turbo pump. The motion of the string was detected by interferometric readout [18]. Based on that, the resonance frequency and $Q$ factor were obtained.

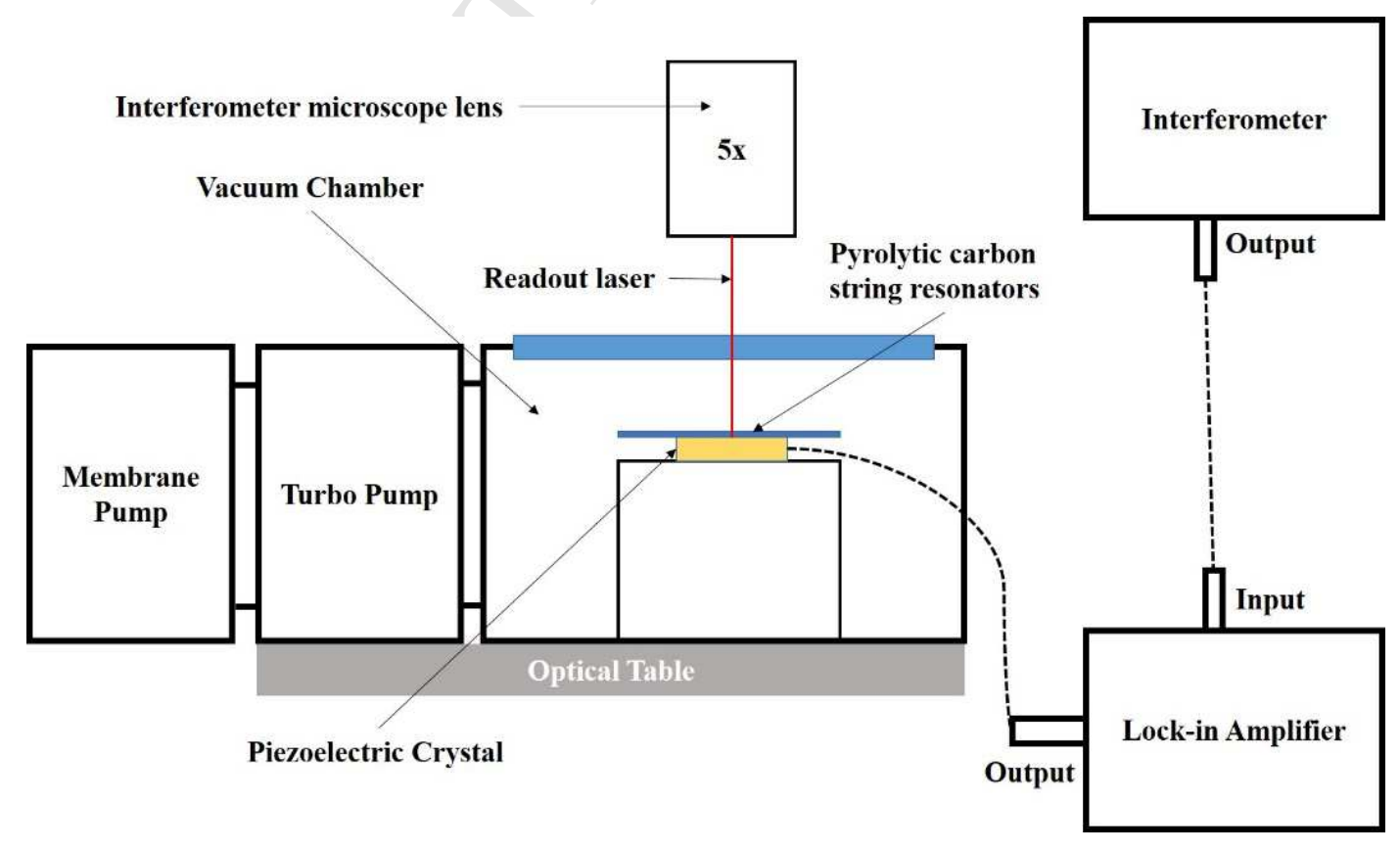


Figure 3: Schematic of setup with piezoelectric actuation and interferometric readout.

\section{Results and Discussion}

3.1 Influence of pyrolysis temperature

The stress in the pyrolytic carbon films determines the performance of the carbon string resonators. The hypothesis of this work was that the stress can be tailored by changing the pyrolysis parameters. The first investigated parameter was the maximum temperature of the process $T_{2}$ which was varied from $500^{\circ} \mathrm{C}$ to $1100^{\circ} \mathrm{C}$. For each processing condition, thin films of pyrolyzed resist with the same initial thickness as the string structures were prepared to measure the residual stress in the carbon material. All the samples processed with different pyrolysis parameters were characterized by thickness measurements, thin film stress measurements and resonance frequency measurements as described above. Figure 4(a) shows the thickness and the shrinkage of the carbon films processed at different pyrolysis temperatures. For both photoresists, considerable shrinkage (>80\%) was observed during pyrolysis with most of the shrinkage taking place at temperatures below $500^{\circ} \mathrm{C}$. Furthermore, the thickness of the carbon layer decreased when the temperature was increased. The final thickness of the carbon layer obtained with SU-8 photoresist was similar to the one obtained with AZ5214E photoresist even though the thickness of SU-8 resist was considerably higher than the thickness of AZ5124E before pyrolysis ( $6 \mu \mathrm{m}$ and $4 \mu \mathrm{m}$, respectively). This means that there was more shrinkage for the SU-8 resist even though it was crosslinked before pyrolysis.

a)

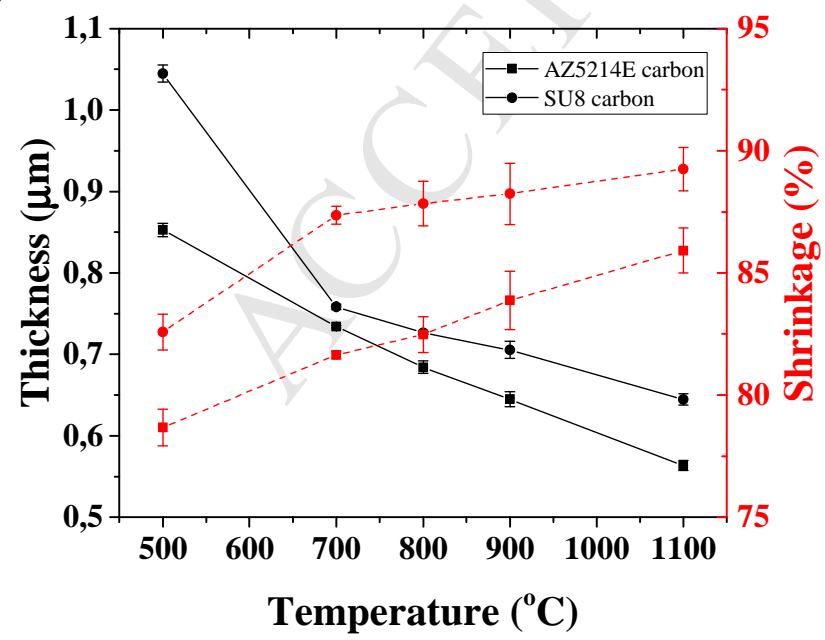

b)

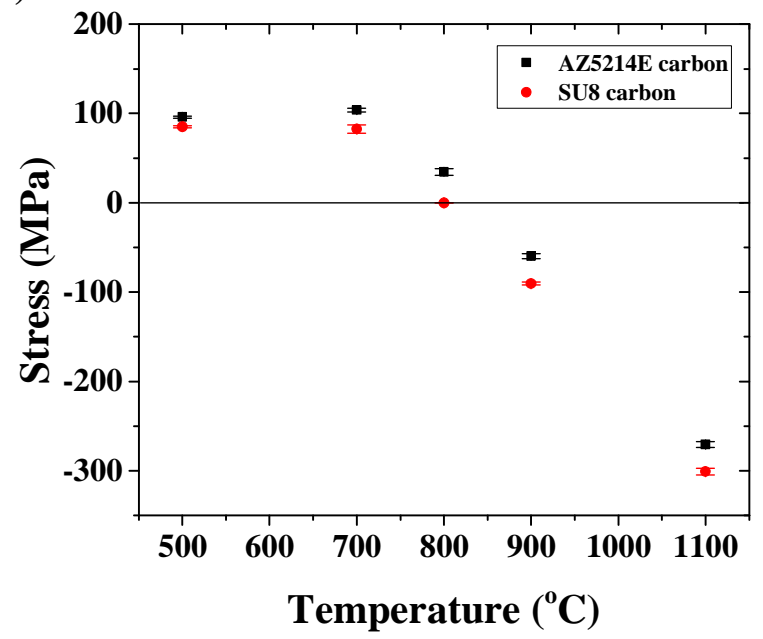


Figure 4: Thickness (full lines), shrinkage (stipulated lines) (a) and stress (b) of the pyrolytic carbon films obtained from AZ5214E and SU-8 at variable temperature. Data is presented as mean \pm SD

(thickness $n=3$, stress $n=6$ ).

Figure 4(b) summarizes the stress measurement results for pyrolytic carbon thin films obtained from both AZ5214E and SU-8. The results show that two stress regimes can be identified: below a pyrolysis temperature of $800^{\circ} \mathrm{C}$ the stress was tensile and above $800^{\circ} \mathrm{C}$ the stress was compressive. In general, the stress is slightly more compressive/less tensile for SU-8/carbon compared to AZ/carbon.

The results on thickness and shrinkage shown in Figure 4(a) are in good agreement with other studies $[19,20]$. Shrinkage is mostly attributed to mass loss in the early phase of the pyrolysis process at around $300^{\circ} \mathrm{C}$ to $500^{\circ} \mathrm{C}$, where the photoresist film starts to be converted into a pyrolytic carbon film [21]. Pyrolytic carbon consists of disordered carbon layers, which are stacked and held together in a distorted way. Below $800^{\circ} \mathrm{C}$, the carbon layers are assumed to be rather disordered and the carbon is more amorphous. When pyrolysis temperature is increased to above $800^{\circ} \mathrm{C}$, those layers become more aligned and the pyrolytic carbon layer is more similar to graphite. This was verified by Raman spectroscopy (Figure 5) on carbon layers processed at different temperatures. As seen from the spectra and in research presented by others [20], the (graphitic) G peak at $1602 \mathrm{~cm}^{-1}$ and (amorphous) D peak at $1334 \mathrm{~cm}^{-1}$ have the same height in the low temperature regime which means that the structure contains both graphitic and amorphous regions. In comparison, the graphitic peak is considerably higher than the amorphous peak in the high temperature regime indicating a more graphitic carbon. The slight decrease of the thickness for increasing temperatures observed in Figure 4(a) might be due to both further mass loss and film thinning through rearrangement of carbon bonds to obtain a more graphitic structure. 


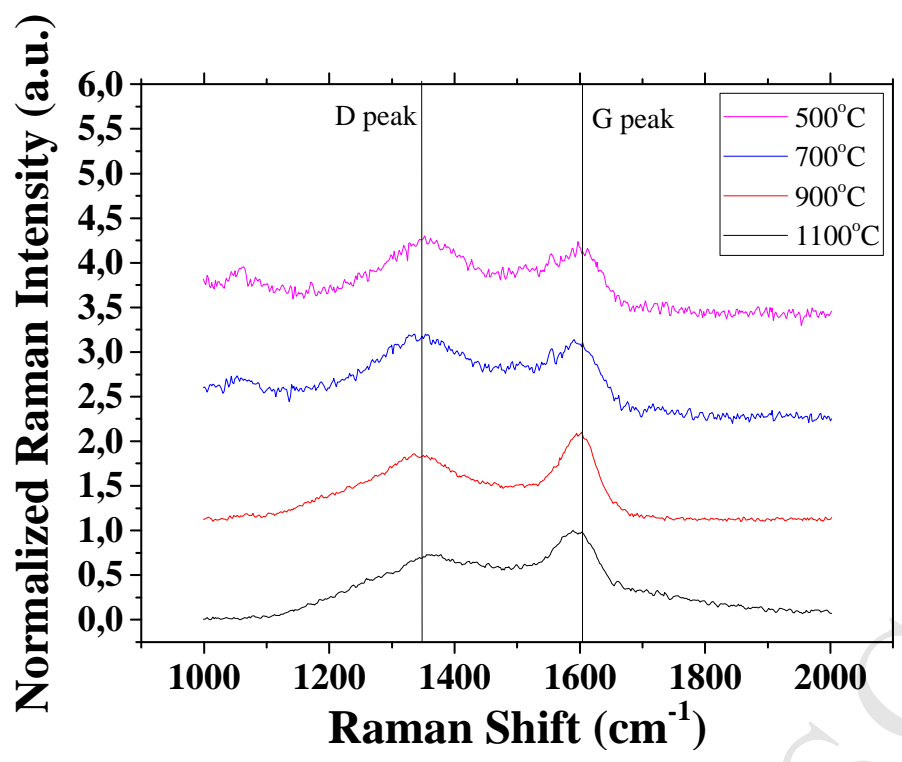

Figure 5: Raman spectra of pyrolytic SU-8/carbon processed at different temperatures.

For better understanding of the influence of the pyrolysis temperature on the stress in the carbon thin films the different sources of stress should be considered. In our study, the stress might originate from two main phenomena: i) the shrinkage of the carbon material due to mass loss results in intrinsic stress and ii) the mismatch of the coefficient of thermal expansion (CTE) between the silicon substrate and the pyrolytic carbon causing bending of the device layer during the cooling step after pyrolysis and generating extrinsic thermal stress.

The intrinsic stress due to mass loss is expected to be tensile, and seems to be a dominating contribution in the temperature regime below $800^{\circ} \mathrm{C}$. In this regime, the CTE of the not fully pyrolyzed carbon is probably similar to or higher than the one of $\mathrm{Si}$, resulting in comparatively negligible or tensile thermal stress. In the regime with pyrolysis temperatures above $800^{\circ} \mathrm{C}$, the residual stress in the carbon films is probably dominated by thermal stress. Apparently, the CTE of the more graphitic carbon is smaller than the one of Si resulting in compressive stress. Indeed, graphite is reported to have low or even negative CTE values [22, 23]. The thermal stress due to the CTE mismatch is higher for processing at higher temperature. At the same time, the elevated temperatures probably result in annealing of the intrinsic tensile stress obtained due to shrinkage or even might result in compressive intrinsic stress due to rearrangement of the material in a more graphitic structure. This rearrangement might also explain the more compressive/less tensile stress for SU-8/carbon compared to AZ/carbon, although no significant differences between the two photoresist precursors in graphitic and amorphous peaks could be identified by Raman 
spectroscopy. To evaluate the hypothesis of a low CTE of pyrolytic carbon, additional thin film samples were prepared on fused silica $(500 \mu \mathrm{m}$ dsp) substrates with a lower CTE than $\mathrm{Si}(0.5 \mathrm{ppm} / \mathrm{K}$ vs $2.6 \mathrm{ppm} / \mathrm{K}$ ). The resulting compressive stress for those samples processed at $1100^{\circ} \mathrm{C}$ was much lower than for Si substrates in case of carbon made from SU-8 (157 MPa and $300 \mathrm{MPa}$ for fused silica and silicon substrate, respectively). Meanwhile, the stress of the AZ-carbon changed from compressive to tensile stress with fused silica substrates. These results confirmed that the thermal stress can be reduced by choosing other substrate materials.

The string structures made from both AZ5214E and SU-8 were pyrolyzed at different temperatures, followed by characterization with an interferometer. The resonance frequency and $Q$ factor of pyrolytic carbon resonators with a width of $15 \mu \mathrm{m}$ were obtained and the results are shown in Figure 6. The standard deviation was calculated based on the measurement of 5 different chips.

a)

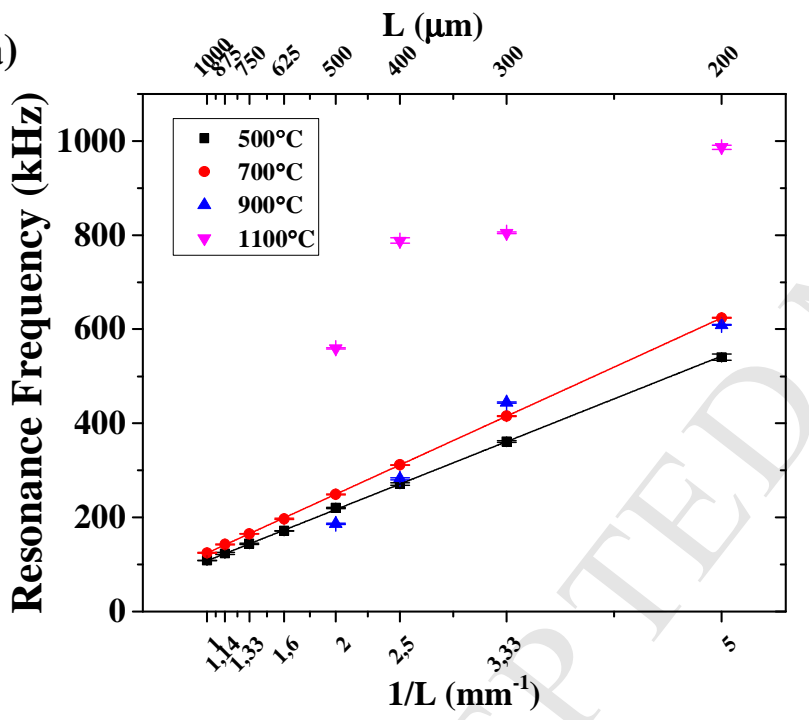

b)

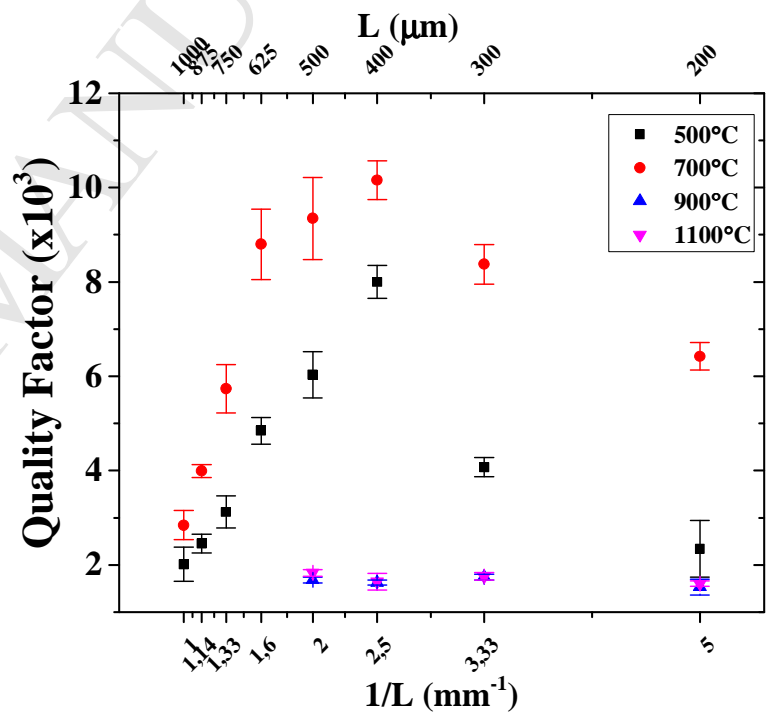


c)

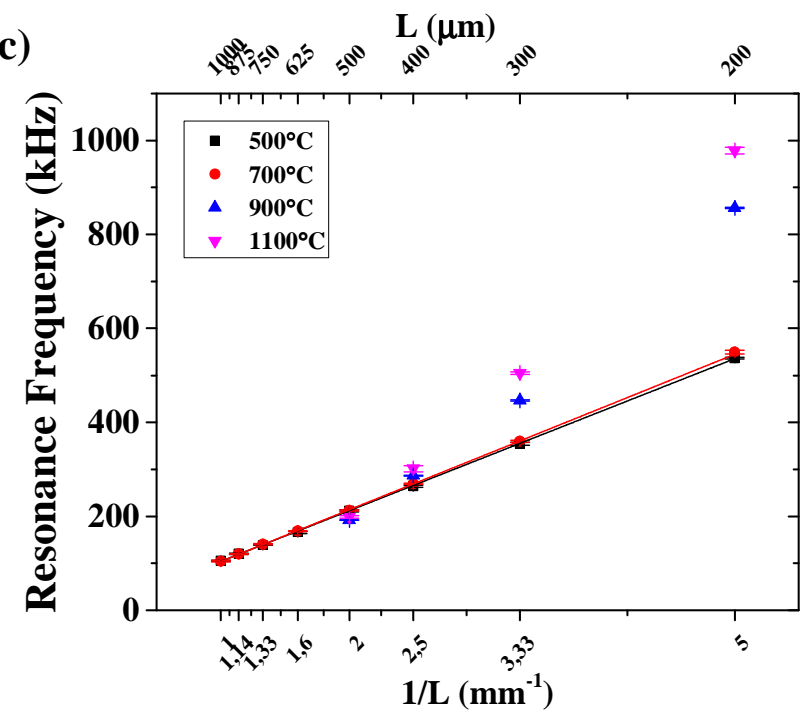

d)

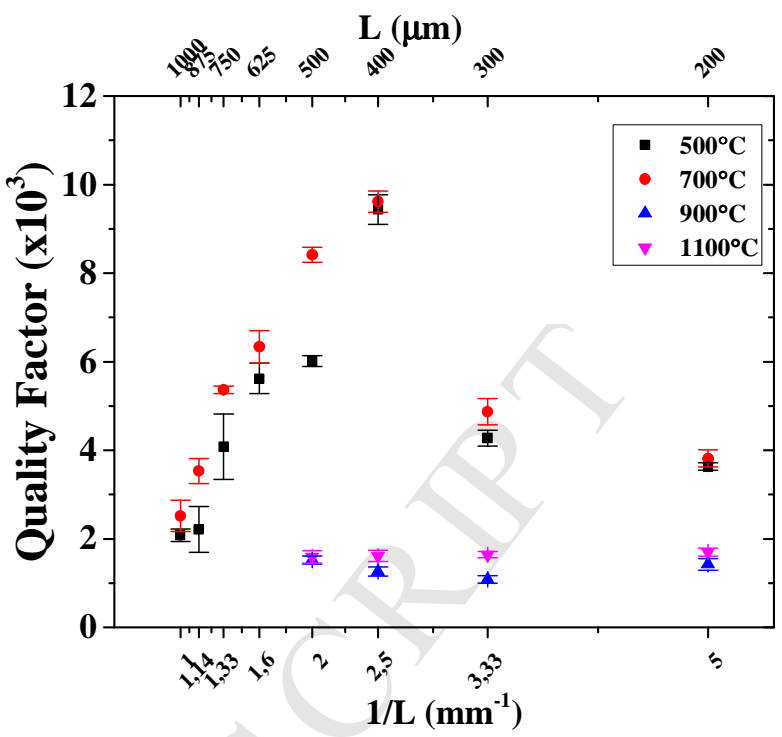

Figure 6: Resonance frequencies and $Q$ factors of pyrolytic carbon string resonators $(15 \mu \mathrm{m}$ width) obtained from AZ5214E ( $a$ and b) and SU-8 (c and d) at different pyrolysis temperatures. Data is presented as mean $\pm \mathrm{SD}(\mathrm{n}=5)$.

The results were similar for both photoresist precursors with slightly higher resonance frequencies and $Q$ factors of the resonators made from AZ5214E compared to SU-8. In the pyrolysis temperature regime below $800^{\circ} \mathrm{C}$, there was a linear dependency of the resonance frequencies on 1/L. This means that according to equation (2) the pyrolytic carbon resonators behave like strings under tensile stress. Meanwhile, in the regime above $800^{\circ} \mathrm{C}$, no linear dependency on $1 / \mathrm{L}$ was observed and all the strings longer than $500 \mu \mathrm{m}$ could not be characterized. This can be explained by the fact that at high temperature, the stress in the pyrolytic carbon changes from tensile to compressive as shown in Figure 4(b). The compressive stress led to a loss of the string-like behavior, buckling of the suspended structures and in particular for longer strings stiction to the substrate (Figure 7). In terms of $Q$ factor, the resonators obtained in the high temperature regime displayed low $Q$ factors due to the compressive stress and the shape of the resonators. In the regime below $800^{\circ} \mathrm{C}$, high quality factors were obtained with the strings with a length of $400 \mu \mathrm{m}$ and 500 $\mu \mathrm{m}$. The reduction of quality factor in short string resonators can be explained by the increase of clamping losses $\left(Q_{\text {clamping }}\right)$. In case of strings longer than $500 \mu \mathrm{m}$, the quality factors also decreased because for longer strings, the area parallel to the substrate increases which results in an increase of the squeeze damping ( $\left.Q_{\text {medium}}\right)$. The higher values of frequency and $\mathrm{Q}$ factor for $\mathrm{AZ} /$ carbon compared to SU-8/carbon resonators are correlated with the higher values of tensile stress as shown 
in figure 4(b). Furthermore, the hardness or density of the pyrolyzed photoresists might be slightly different.
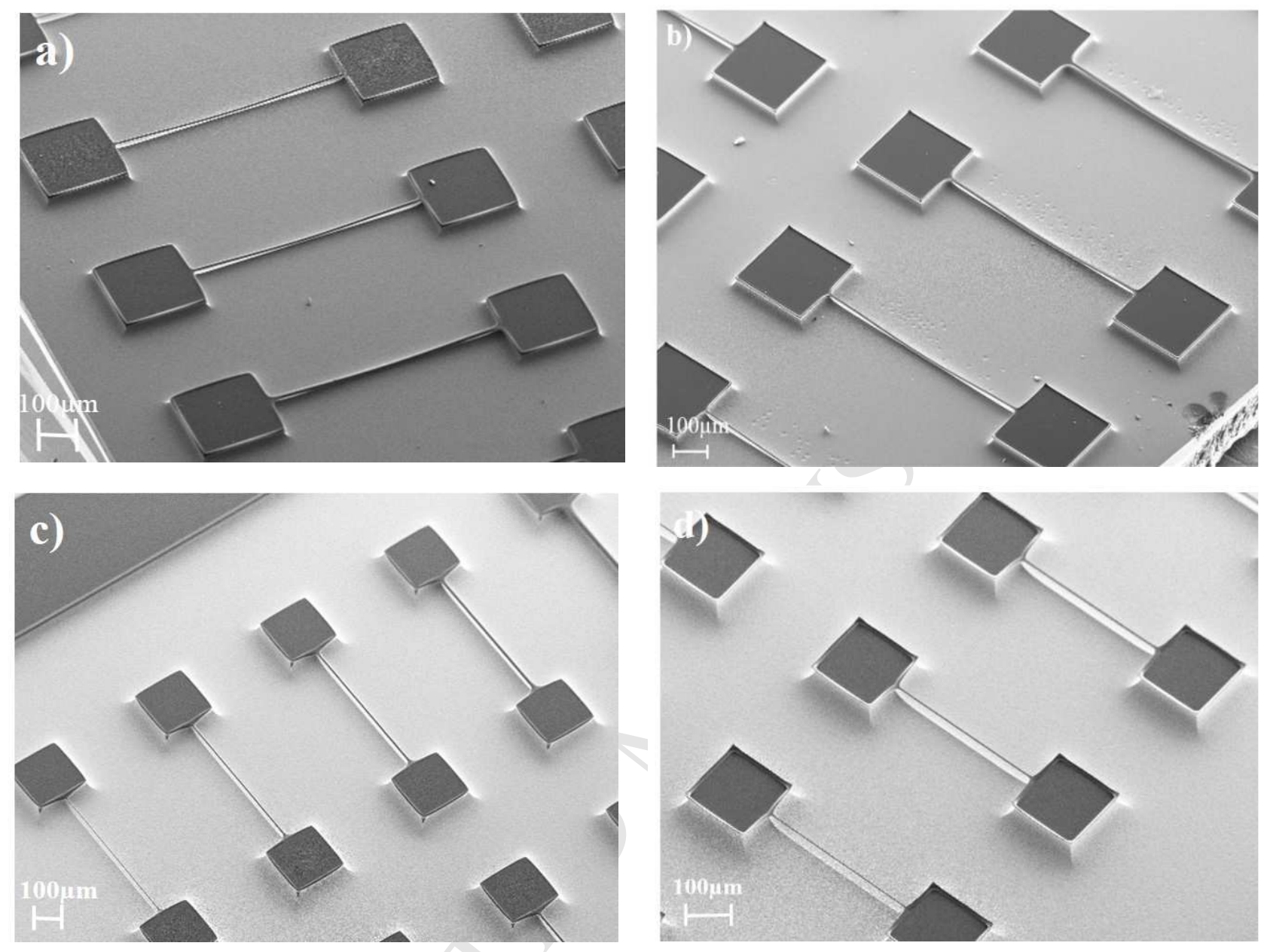

Figure 7: Pyrolytic carbon resonator with $625 \mu \mathrm{m}$ length and width of $10 \mu \mathrm{m}, 15 \mu \mathrm{m}, 20 \mu \mathrm{m}$ at $900^{\circ} \mathrm{C}$ pyrolysis temperature made from (a) AZ5214E (b) SU-8 and at $700^{\circ} \mathrm{C}$ pyrolysis temperature obtained from (c) AZ5214E (d) SU-8.

Table 1: Comparison of tensile stress measured for thin films and calculated for string structures obtained at $500^{\circ} \mathrm{C}$ and $700^{\circ} \mathrm{C}$. Data is presented as mean $\pm \mathrm{SD}(\mathrm{n} \geq 5)$

\begin{tabular}{|c|c|c|c|c|}
\hline & \multicolumn{2}{|c|}{ AZ5214E carbon } & \multicolumn{2}{c|}{ SU-8 carbon } \\
\hline Stress (MPa) & $500^{\circ} \mathrm{C}$ & $700^{\circ} \mathrm{C}$ & $500^{\circ} \mathrm{C}$ & $700^{\circ} \mathrm{C}$ \\
\hline Thin film & $95,9 \pm 1,2$ & $103,9 \pm 2,1$ & $85,2 \pm 1,2$ & $82,5 \pm 4,7$ \\
\hline $400 \mu \mathrm{m}$ string & $66,8 \pm 1,4$ & $88,2 \pm 0,3$ & $67,8 \pm 1,3$ & $70,8 \pm 0,5$ \\
\hline $500 \mu \mathrm{m}$ string & $58,9 \pm 0,7$ & $88,1 \pm 0,5$ & $68,2 \pm 1,6$ & $68,7 \pm 0,7$ \\
\hline
\end{tabular}




\begin{tabular}{|l|l|l|l|l|}
\hline $625 \mu \mathrm{m}$ string & $65,2 \pm 0,4$ & $86,1 \pm 0,9$ & $65,4 \pm 1,8$ & $67,4 \pm 0,9$ \\
\hline $750 \mu \mathrm{m}$ string & $66,1 \pm 1,0$ & $87,2 \pm 0,7$ & $65,8 \pm 0,7$ & $67,5 \pm 1,2$ \\
\hline
\end{tabular}

The measured resonance frequency in the first mode was used to calculate the stress in the string structures using equation (2) and assuming a density of pyrolytic carbon of $1,4 \mathrm{~g} / \mathrm{cm}^{3}$ for AZ5214Ecarbon and $1,5 \mathrm{~g} / \mathrm{cm}^{3}$ for SU-8-carbon [10]. Table 1 shows a comparison of the calculated values with the stress measured for the unpatterned carbon thin films. The results demonstrate excellent agreement between the tensile stress measured in thin films and calculated for string device layers for $500^{\circ} \mathrm{C}$ and $700^{\circ} \mathrm{C}$. However, it was impossible to compare the stress in thin films and strings processed at temperatures of $900^{\circ} \mathrm{C}$ and $1100^{\circ} \mathrm{C}$ because equation (2) only describes string-behaving resonators.

In summary, to obtain string-like behavior of suspended pyrolytic carbon resonators, processing in the low temperature regime below $800^{\circ} \mathrm{C}$ was required. Based on the resonance frequency and $Q$ factor results, the carbon string resonators show best performance at $700^{\circ} \mathrm{C}$ pyrolysis for both AZ5214E and SU-8 (Figure 7c and 7d). This pyrolysis temperature is kept constant for all further experiments.

\subsection{Influence of ramping rate}

The second pyrolysis parameter investigated was the ramping rate $v_{2}$. Four different ramping rates from $2^{\circ} \mathrm{C} / \mathrm{min}$ to $30^{\circ} \mathrm{C} / \mathrm{min}$ were tested. The dwell time at $700^{\circ} \mathrm{C}$ was $90 \mathrm{~min}$. Figure 8 a shows the measured thickness and shrinkage of the carbon thin films obtained with the two types of resist. As it can be seen from the results (Figure 8), when the ramping rate was increased, the thickness of the carbon layer was reduced for both AZ5214E and SU-8. This is similar to what has been observed by Hassan et al [24] and can be attributed to more mass loss due to less time for formation of new carbon bonds. Figure $8 \mathrm{~b}$ shows the stress results for pyrolytic carbon thin film for AZ5214E and SU-8. 
a)

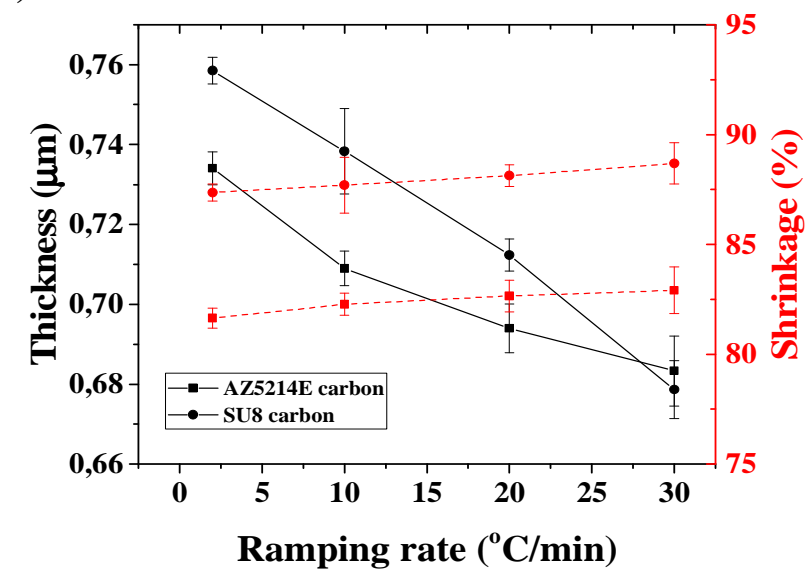

b)

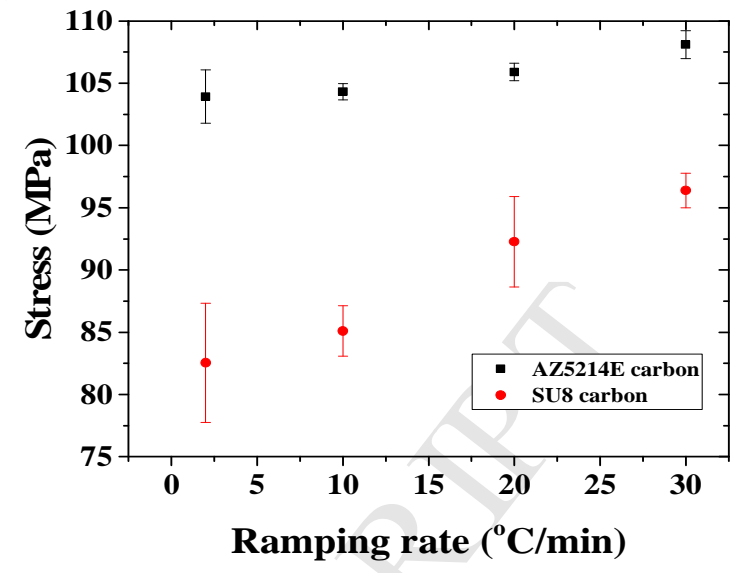

Figure 8: Thickness (full lines), shrinkage (stipulated lines) (a) and tensile stress (b) of the pyrolytic carbon films obtained from AZ5214E and SU-8 at variable ramping rate. Data is presented as mean $\pm S D$ (thickness $n=3$, stress $n=6$ ).

a)

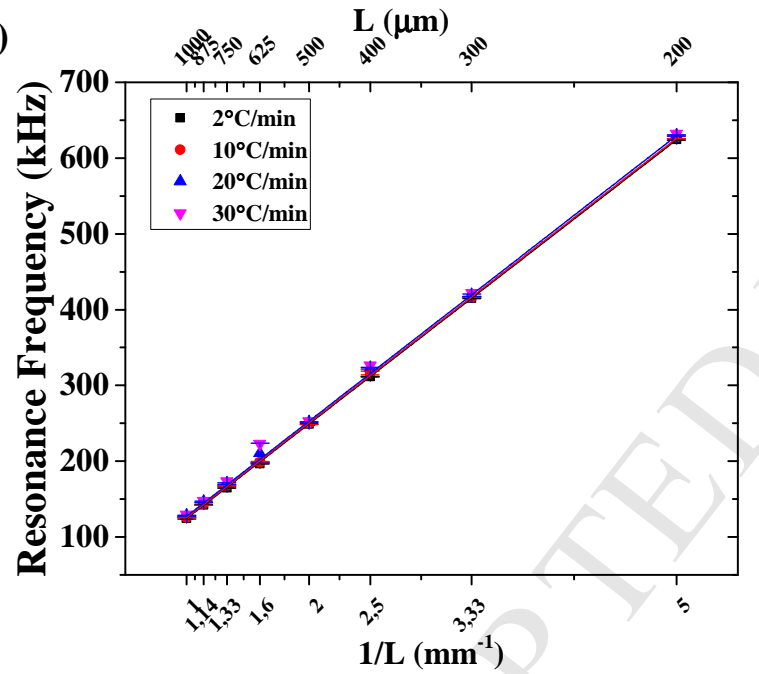

c)

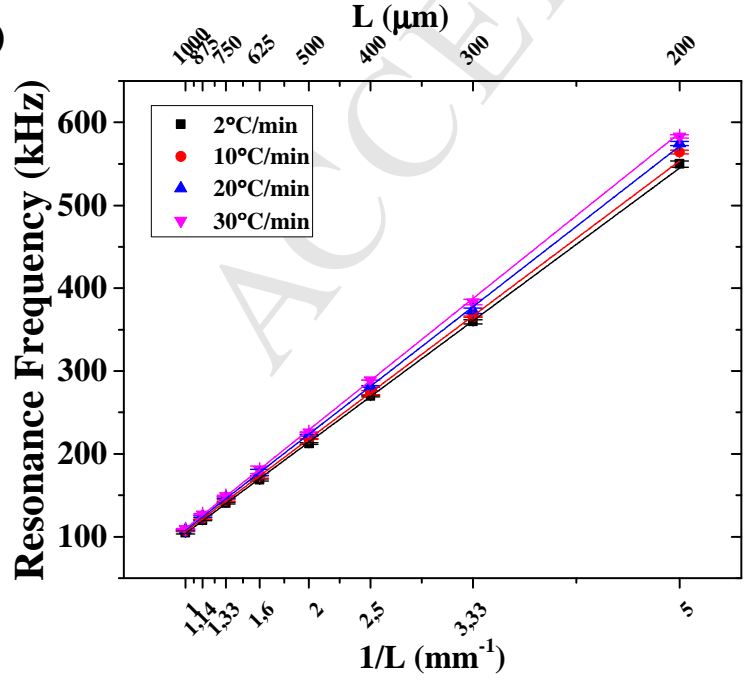

b)

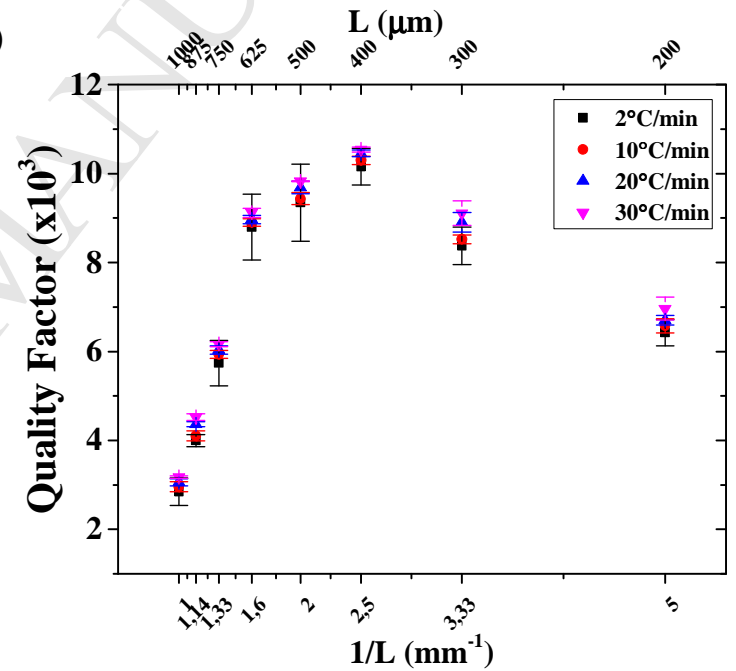

d)

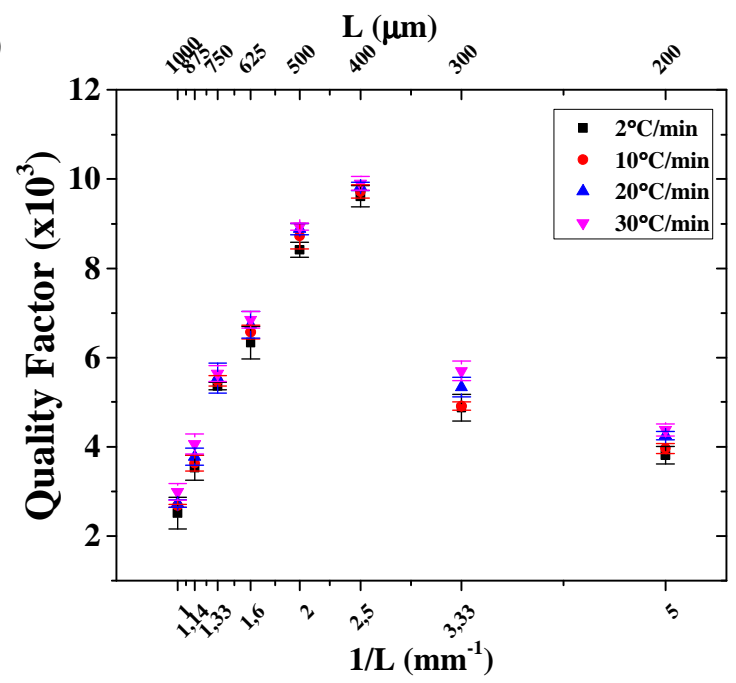


Figure 9: Resonance frequencies and $Q$ factors of pyrolytic carbon string resonators $(15 \mu \mathrm{m}$ width) obtained from AZ5214E ( $a$ and b) and SU-8 (c and d) with different pyrolysis ramping rates. Data is presented as mean $\pm \operatorname{SD}(n=5)$.

Similar to Figure 4(b), the tensile stress in AZ5214E carbon films was slightly higher than in SU-8 carbon films. In particular for SU-8 the tensile stress in the pyrolytic carbon films increases for increasing ramping rates. At $700^{\circ} \mathrm{C}$, it is assumed that the tensile stress is intrinsic stress caused by the shrinkage of the film, which is more important for higher ramping rates and for SU-8 compared to $\mathrm{AZ}$ photoresist.

The results of the resonance frequencies and $Q$ factors of the pyrolytic carbon string resonators are summarized in Figure 9. All measured devices display string-like resonant behavior with linear dependency on 1/L. For AZ5124E carbon resonators, there was a minor increase in resonance frequencies when the ramping rate was increased. In comparison, the resonance frequencies of the pyrolytic carbon string obtained with SU-8 showed a slightly more prominent increase. The $Q$ factor also slightly increased when the ramping rates is increased from $2^{\circ} \mathrm{C} / \mathrm{min}$ to $30^{\circ} \mathrm{C} / \mathrm{min}$. Those results are in excellent agreement with the trends observed for the stress measurements. The high ramping rate generates higher tensile stresses in the strings which results in improved mechanical properties.

From the resonance frequency, the stress in the string was calculated as described in the previous section and the results are shown in Table 2. The values confirm that the tensile stress in both carbon thin film and carbon string structure obtained with AZ5214E are higher than in the ones obtained with SU-8 at different ramping rates. However, in both materials, slightly higher tensile stress can be obtained at higher ramping rate.

Table 2: Comparison of tensile stress between thin film and string structures at different ramping rates. Data is presented as mean $\pm \mathrm{SD}(\mathrm{n} \geq 5)$

\begin{tabular}{|c|c|c|c|c|}
\hline & \multicolumn{4}{|c|}{ AZ5214E carbon } \\
\hline Stress (MPa) & $2^{\circ} \mathrm{C} / \mathrm{min}$ & $10^{\circ} \mathrm{C} / \mathrm{min}$ & $20^{\circ} \mathrm{C} / \mathrm{min}$ & $30^{\circ} \mathrm{C} / \mathrm{min}$ \\
\hline Thin film & $103,9 \pm 2,1$ & $104,3 \pm 0,6$ & $105,9 \pm 0,7$ & $108,1 \pm 1,1$ \\
\hline $400 \mu \mathrm{m}$ string & $88,2 \pm 0,2$ & $90,9 \pm 1,4$ & $94,5 \pm 0,6$ & $96,9 \pm 0,7$ \\
\hline $500 \mu \mathrm{m}$ string & $88,1 \pm 0,5$ & $88,8 \pm 0,9$ & $89,9 \pm 0,2$ & $90,7 \pm 0,2$ \\
\hline $625 \mu \mathrm{m}$ string & $86,0 \pm 0,9$ & $87,5 \pm 0,6$ & $98,5 \pm 1,2$ & $110,6 \pm 2,7$ \\
\hline $750 \mu \mathrm{m}$ string & $87,2 \pm 0,7$ & $89,9 \pm 0,8$ & $93,0 \pm 1,2$ & $96,3 \pm 1,6$ \\
\hline & \multicolumn{4}{|c|}{$\mathrm{SU}-8$ carbon } \\
\hline & $2^{\circ} \mathrm{C} / \mathrm{min}$ & $10^{\circ} \mathrm{C} / \mathrm{min}$ & $20^{\circ} \mathrm{C} / \mathrm{min}$ & $30^{\circ} \mathrm{C} / \mathrm{min}$ \\
\hline
\end{tabular}




\begin{tabular}{|c|l|l|l|l|}
\hline Thin film & $82,5 \pm 4,7$ & $85,1 \pm 2,0$ & $92,2 \pm 3,6$ & $96,3 \pm 1,3$ \\
\hline $400 \mu \mathrm{m}$ string & $70,7 \pm 0,5$ & $72,9 \pm 1,3$ & $77,1 \pm 0,6$ & $81,2 \pm 0,1$ \\
\hline $500 \mu \mathrm{m}$ string & $68,7 \pm 0,7$ & $72,2 \pm 0,3$ & $75,2 \pm 0,7$ & $77,6 \pm 0,3$ \\
\hline $625 \mu \mathrm{m}$ string & $67,4 \pm 0,9$ & $70,6 \pm 1,2$ & $74,8 \pm 3,2$ & $77,5 \pm 3,8$ \\
\hline $750 \mu \mathrm{m}$ string & $67,5 \pm 1,2$ & $70,4 \pm 1,0$ & $74,1 \pm 0,9$ & $76,1 \pm 0,6$ \\
\hline
\end{tabular}

\subsection{Influence of dwell time}

The third parameter of the pyrolysis process which was examined is the dwelling time $t_{2}$. The samples were pyrolyzed at $700^{\circ} \mathrm{C}$ for $10 \mathrm{~min}, 90 \mathrm{~min}, 300 \mathrm{~min}$ and $600 \mathrm{~min}$, respectively and the ramping rate was $2^{\circ} \mathrm{C} / \mathrm{min}$. The results for carbon thin films are shown in Figure 10 . With the increase of dwell time from 10 min to 600 mins, the thickness of the carbon films clearly decreased. In parallel, the tensile stress contained in those films was reduced for longer pyrolysis processes. The decrease in thickness for longer dwell time could be explained by continued mass loss or the reorganization of the carbon domains in the film promoting the formation of more graphitic carbon and densification. The prolonged processing at high temperature and the reordering of the carbon might lead to annealing of the intrinsic tensile stress due to shrinkage. Furthermore, the resulting carbon material should according to the previous discussions display a lower CTE than more disordered carbon resulting in reduced thermal stress components. The observation of decreased tensile stress in the thin film structure was confirmed by the measurements with string structures. Figure 11 shows the resonance frequency response and $Q$ factors of AZ5214E carbon and SU-8 carbon string resonators.

a)

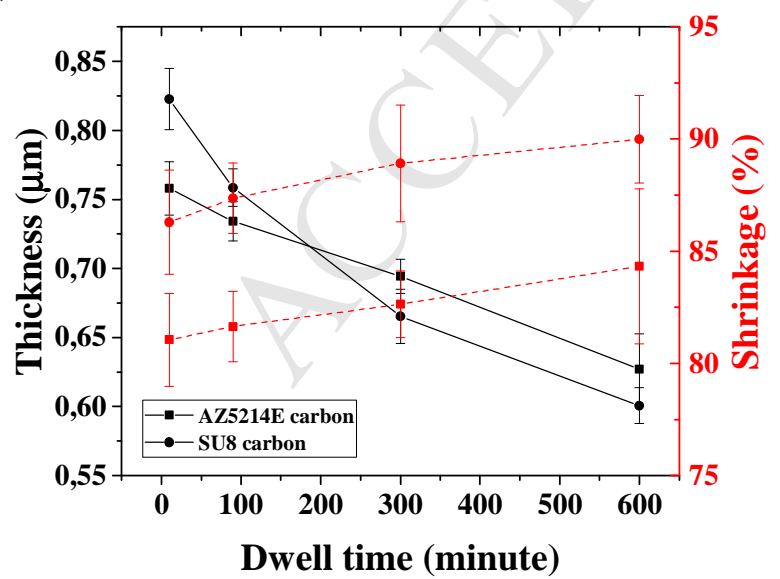

b)

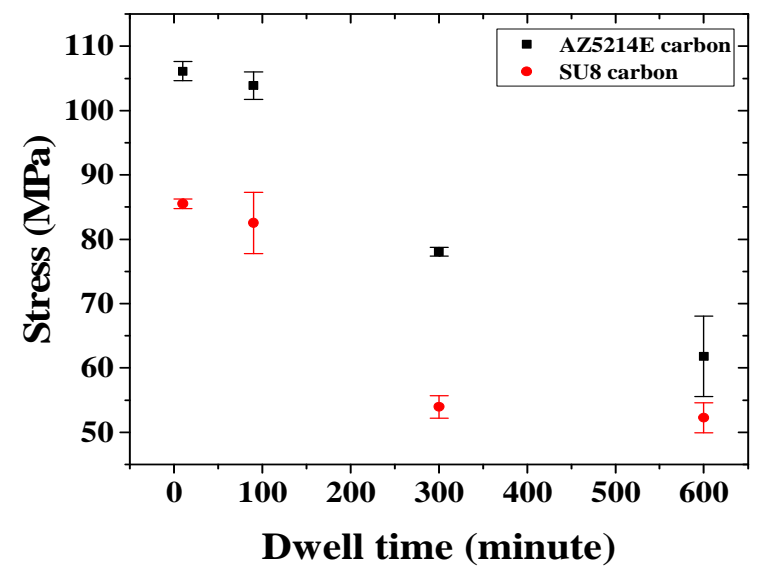


Figure 10: Thickness (full lines), shrinkage (stipulated lines) (a) and stress (b) of the pyrolytic carbon films obtained from AZ5214E and SU-8 based on dwell time. Data is presented as mean \pm SD (thickness $n=3$, stress $n=6$ ).

a)

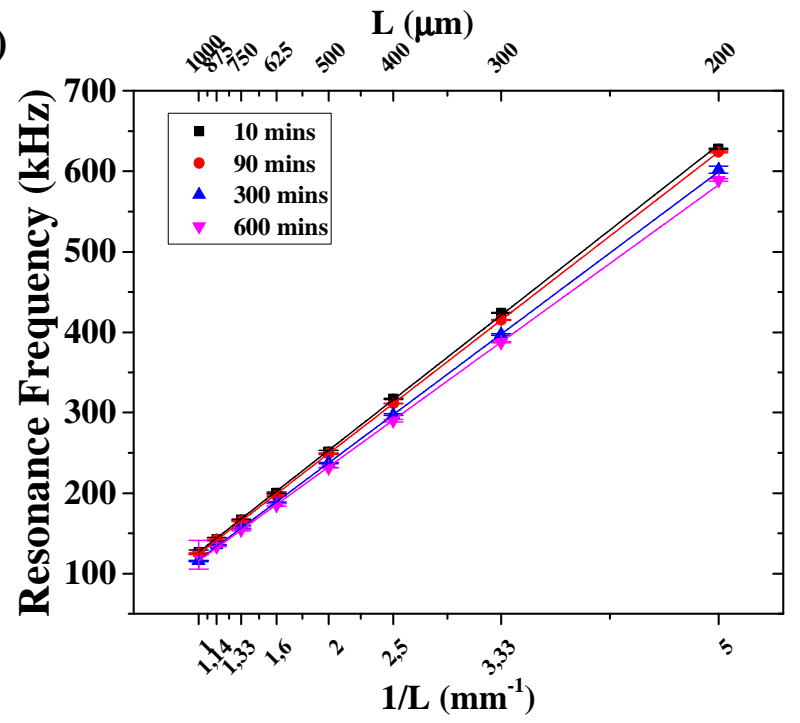

c)

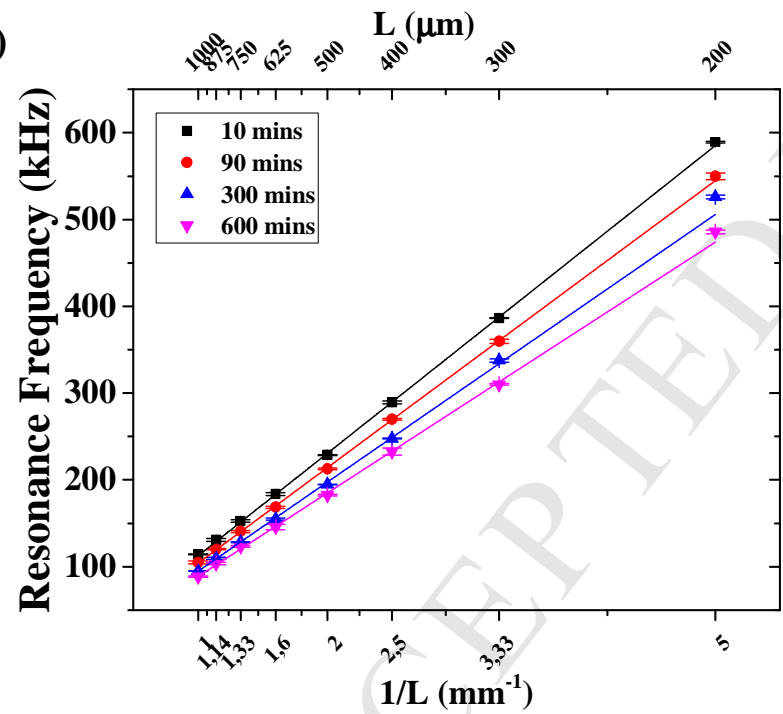

b)

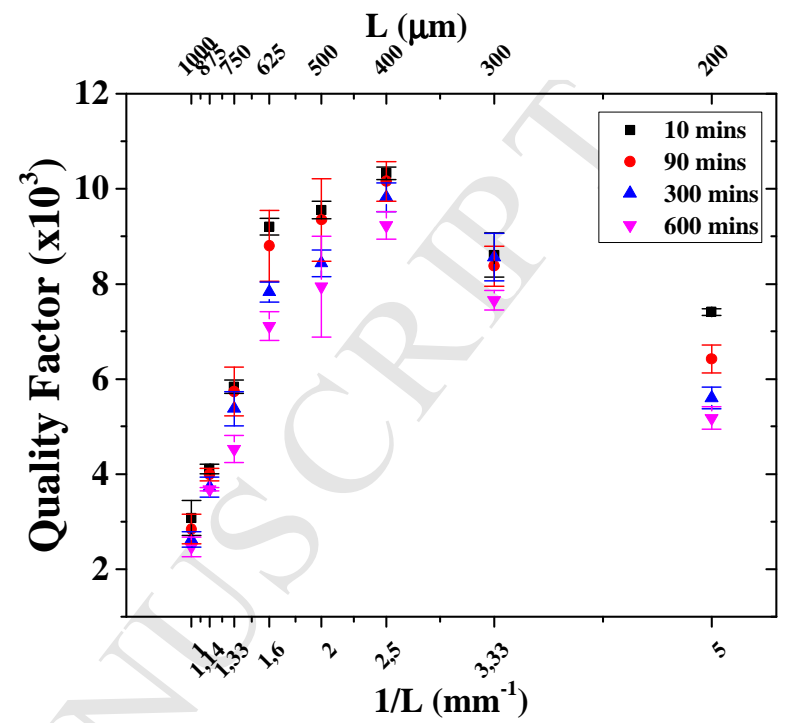

d)

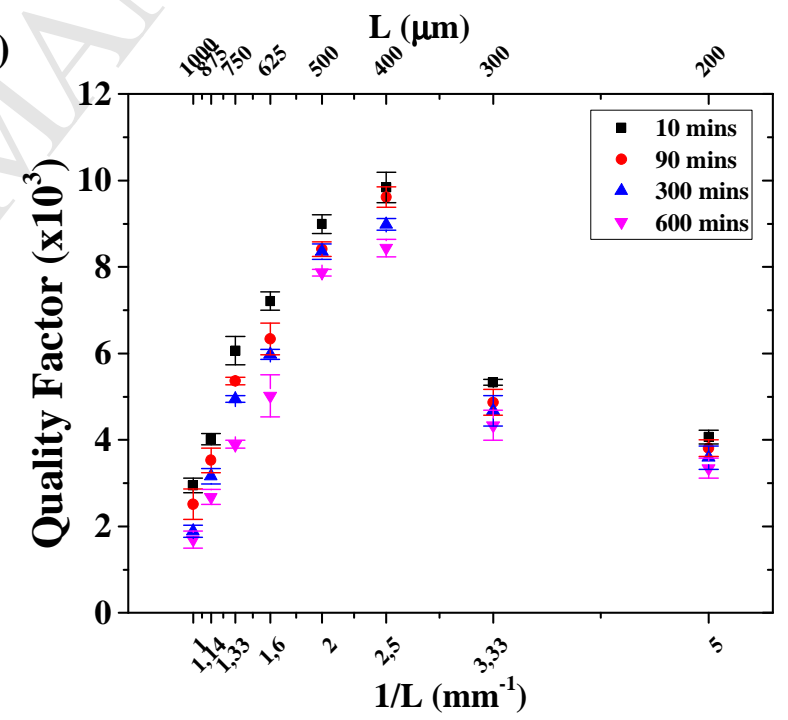

Figure 11: Resonance frequencies and $Q$ factors of pyrolytic carbon string resonators $(15 \mu \mathrm{m}$ width) obtained from AZ5214E ( $a$ and b) and SU-8 (c and d) with different pyrolysis dwell time. Data is presented as mean $\pm \operatorname{SD}(\mathrm{n}=5)$.

The fabricated resonators all displayed string-like resonant behavior due to the fact that the pyrolysis temperature was comfortably below $800^{\circ} \mathrm{C}$. However, it clearly appeared that for short dwell time $(10 \mathrm{~min})$ the resonance frequencies and the quality factors were highest. The calculated tensile stress contained in the string structure presented in Table 3 also confirmed that for shorter dwell time, the tensile stress in both AZ5214E carbon and SU-8 carbon was higher. 
Table 3: Comparison of tensile stress between thin film and string structures at different dwell times. Data is presented as mean $\pm \mathrm{SD}(\mathrm{n} \geq 5)$

\begin{tabular}{|c|c|c|c|c|}
\hline & \multicolumn{4}{|c|}{ AZ5214E carbon } \\
\hline Stress (MPa) & 10 minutes & 90 minutes & 300 minutes & 600 minutes \\
\hline Thin film & $106,1 \pm 1,5$ & $103,9 \pm 2,13$ & $78,3 \pm 0,7$ & $61,7 \pm 6,2$ \\
\hline $400 \mu \mathrm{m}$ string & $91,5 \pm 0,5$ & $88,2 \pm 0,25$ & $80,5 \pm 0,6$ & $76,5 \pm 0,8$ \\
\hline $500 \mu \mathrm{m}$ string & $89,7 \pm 1,1$ & $88,1 \pm 0,47$ & $80,1 \pm 0,4$ & $76,2 \pm 0,1$ \\
\hline $625 \mu \mathrm{m}$ string & $89,2 \pm 0,9$ & $86,0 \pm 0,9$ & $78,5 \pm 0,8$ & $76,3 \pm 1,2$ \\
\hline $750 \mu \mathrm{m}$ string & $89,2 \pm 0,5$ & $87,2 \pm 0,73$ & $79,6 \pm 1,6$ & $76,3 \pm 1,1$ \\
\hline & \multicolumn{5}{|c|}{ SU-8 carbon } & 600 minutes \\
\hline & 10 minutes & 90 minutes & 300 minutes & $52,2 \pm 2,3$ \\
\hline Thin film & $85,5 \pm 0,7$ & $82,5 \pm 0,7$ & $53,9 \pm 0,6$ & $52,6 \pm 1,8$ \\
\hline $400 \mu \mathrm{m}$ string & $81,4 \pm 1,0$ & $70,7 \pm 0,5$ & $59,5 \pm 0,2$ & $50,5 \pm 0,5$ \\
\hline $500 \mu \mathrm{m}$ string & $79,4 \pm 0,3$ & $68,7 \pm 0,7$ & $57,6 \pm 0,2$ & $50,4 \pm 2,0$ \\
\hline $625 \mu \mathrm{m}$ string & $80,1 \pm 1,3$ & $67,4 \pm 0,9$ & $56,8 \pm 0,9$ & $52,1 \pm 0,8$ \\
\hline $750 \mu \mathrm{m}$ string & $79,5 \pm 1,4$ & $67,5 \pm 1,2$ & $56,2 \pm 0,5$ & \\
\hline
\end{tabular}

In conclusion, the pyrolytic carbon shows the best mechanical properties for fabrication of string resonators as expressed through resonance frequency and $Q$ factor for pyrolysis at $700^{\circ} \mathrm{C}$ maximum temperature, high ramping rate and short dwell time. The results also showed that dwell time had more impact than the ramping rate. Furthermore, the string resonators with length $\mathrm{L}=400-500 \mu \mathrm{m}$ consistently demonstrated the best performance in terms of quality factor while still providing a reasonably high resonance frequency compared to longer strings. Therefore, the final characterization was performed with the optimized $400 \mu \mathrm{m}$ pyrolytic carbon string resonators fabricated at $700^{\circ} \mathrm{C}$ maximum temperature, $30^{\circ} \mathrm{C} / \mathrm{min}$ ramping rate and 10 minutes dwell time.

3.4 Performance and time stability of pyrolytic carbon string optimized resonators

\subsubsection{Time stability}

In MEMS, devices are often stored for a long period of time prior to operation. Therefore, the influence of storage on the performance is an important factor to consider. Especially for MEMS resonators, pyrolytic carbon is expected to be more influenced by e.g. humidity than traditional materials for MEMS fabrication such as $\mathrm{SiN}$ or $\mathrm{Si}$. Therefore, initial experiments on the time stability of pyrolytic carbon string resonators were performed. The pyrolytic carbon strings were 
characterized immediately after fabrication. Then, the samples were stored in standard laboratory environment and characterized again over time. Figure 12 shows that both pyrolytic carbon strings obtained with AZ5214E and SU-8 displayed only a minor decrease in resonance frequency during storage indicating that the tensile stress in the pyrolytic carbon was not significantly released due to creep or physical aging during the period of observation.

a)

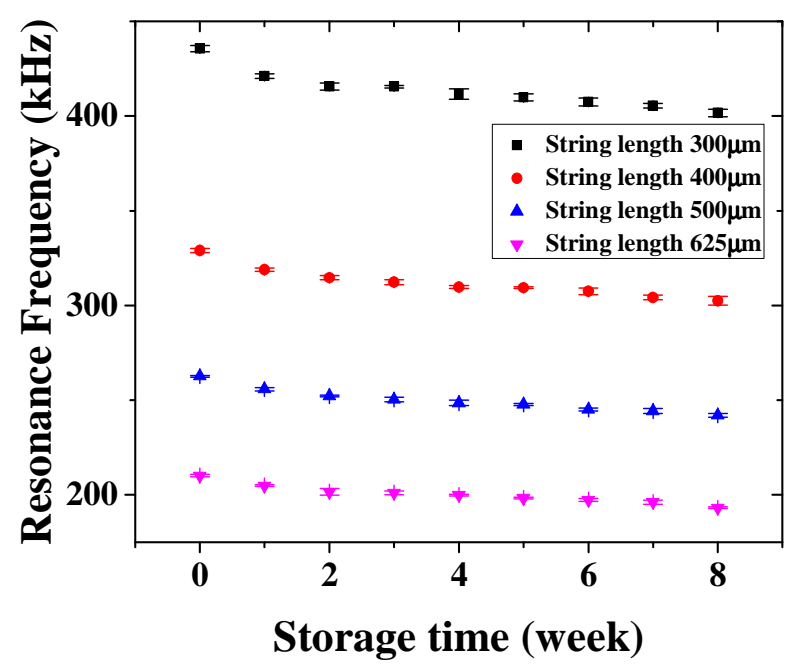

c)

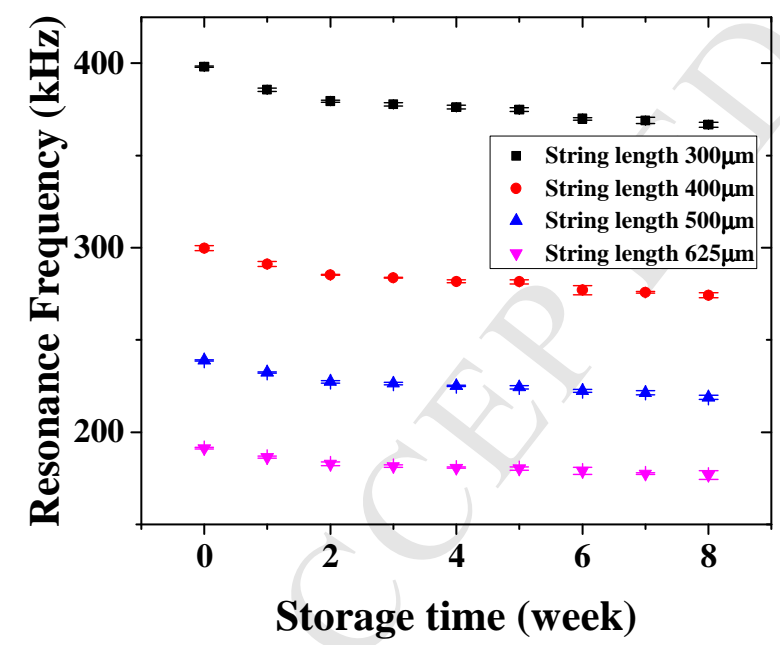

b)

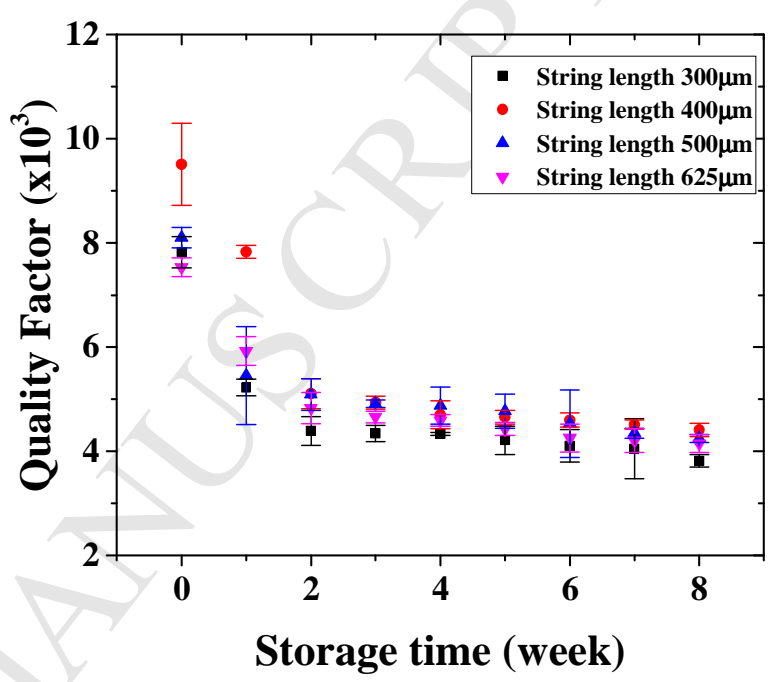

d)

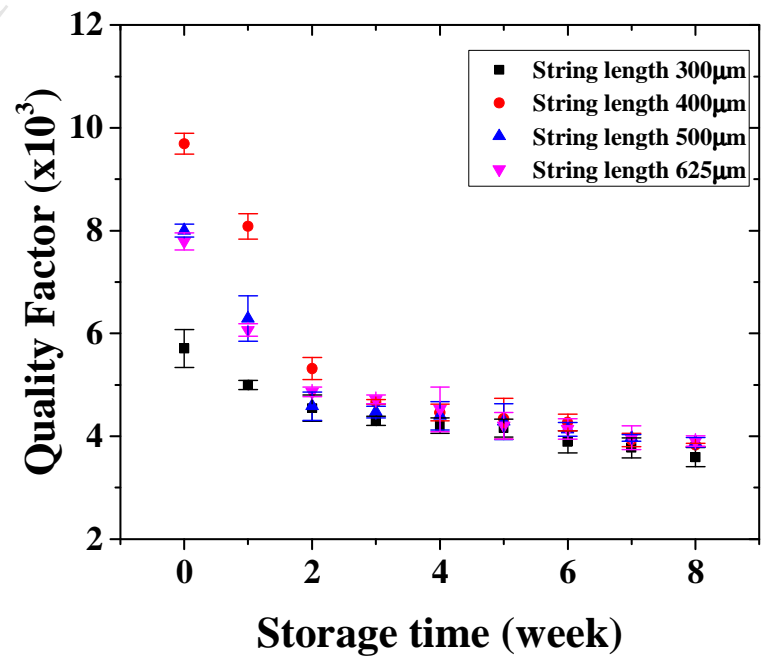

Figure 12: Aging effect on resonance frequencies and $Q$ factors of pyrolytic carbon string resonator made from AZ5214E (a and b) and SU-8 (c and d).

However, a major decrease of $Q$ factor of the string resonators occurred during the first 2 weeks of storage after which the further decrease was small. The reason for this performance loss is probably that the carbon structure absorbed water from the atmosphere on the surface which increased the surface damping and reduced the quality factor $\left(Q_{\text {surface }}\right.$ or $\left.Q_{\text {other }}\right)$. According to the results, the 
carbon strings obtained from SU-8 were slightly more stable than the ones fabricated with AZ5214E. For recovering the performance of the devices, we tried to re-heat the pyrolytic carbon string resonators in an oven at $120^{\circ} \mathrm{C}$ for 1 hour. The resonance frequency and $Q$ factor started slowly to recover. However, for full recovering, further investigation needs to be performed.

\subsubsection{Performance stability}

For the systematic study in this work, all measurements with resonators were performed in high vacuum $\left(<10^{-5} \mathrm{mbar}\right)$. For further investigation, the optimized SU-8/carbon string resonators (Length $400 \mu \mathrm{m}$, width $15 \mu \mathrm{m})$ were also characterized in low vacuum $\left(\sim 10^{-2}\right.$ mbar) and ambient conditions. The results are shown in Figure 13. As expected the added mass of the gas surrounding the resonators decreases the resonance frequency, while the viscous damping of the environment dissipates energy resulting in a lower $Q$ factor. Especially, at ambient conditions where most energy is dissipated through the surrounding media the device performance is comparable to traditional MEMS materials.

When compared to state of the art SiN string resonators, the resonance frequencies and $Q$ factors of the optimized pyrolytic carbon resonators are generally slightly lower [25]. However, in sensor applications the limit of detection is generally defined by the noise in the measurement. The Allan Deviation which defines the minimum detectable fractional frequency shift with a SNR of 1 is on par with state of the art SiN resonators, with values below $1 \mathrm{ppm}$ at a bandwidth of $100 \mathrm{~Hz}$ [12]. Furthermore, this measurement shows that the limiting noise contribution is from the random low frequency fluctuations in the laser of the read out system and not the resonator itself.

a)

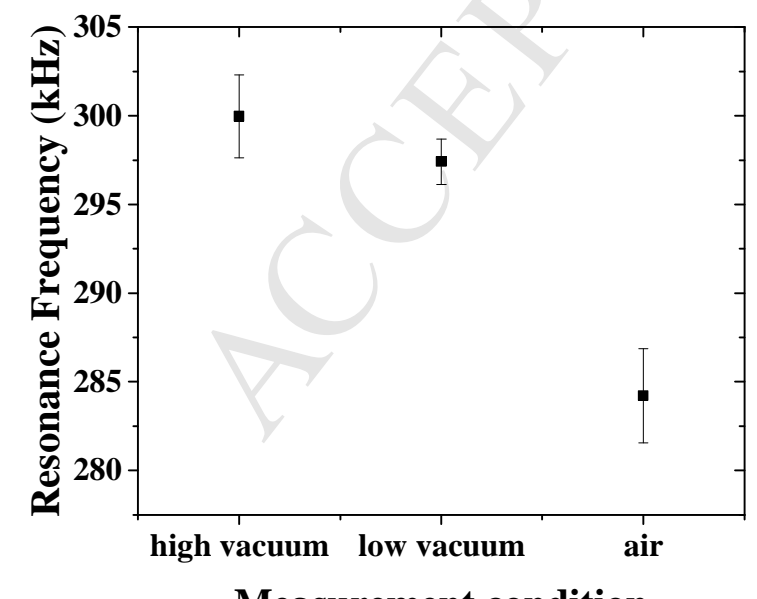

b)

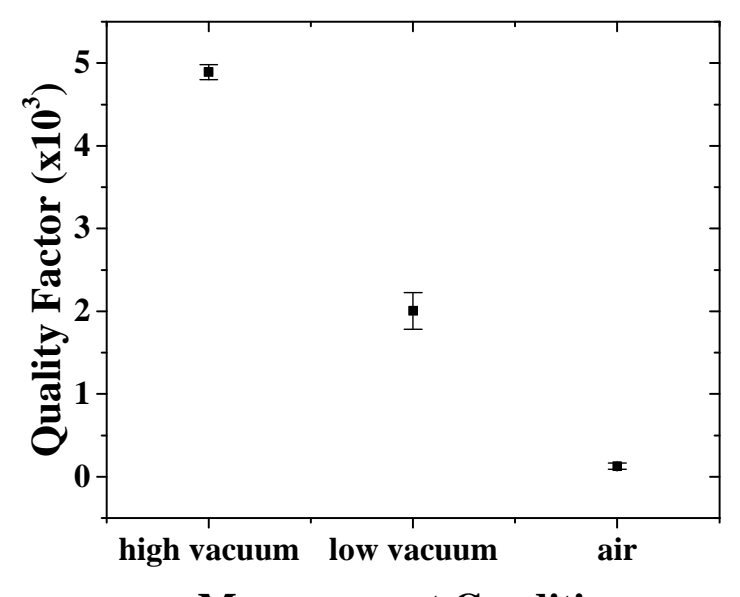

Measurement Condition

Figure 13: Resonance frequency (a) and $Q$ factor (b) of the optimized SU-8/carbon string resonators $(\mathrm{L}=400 \mu \mathrm{m}, \mathrm{w}=15 \mu \mathrm{m})$ in different measurement conditions. 


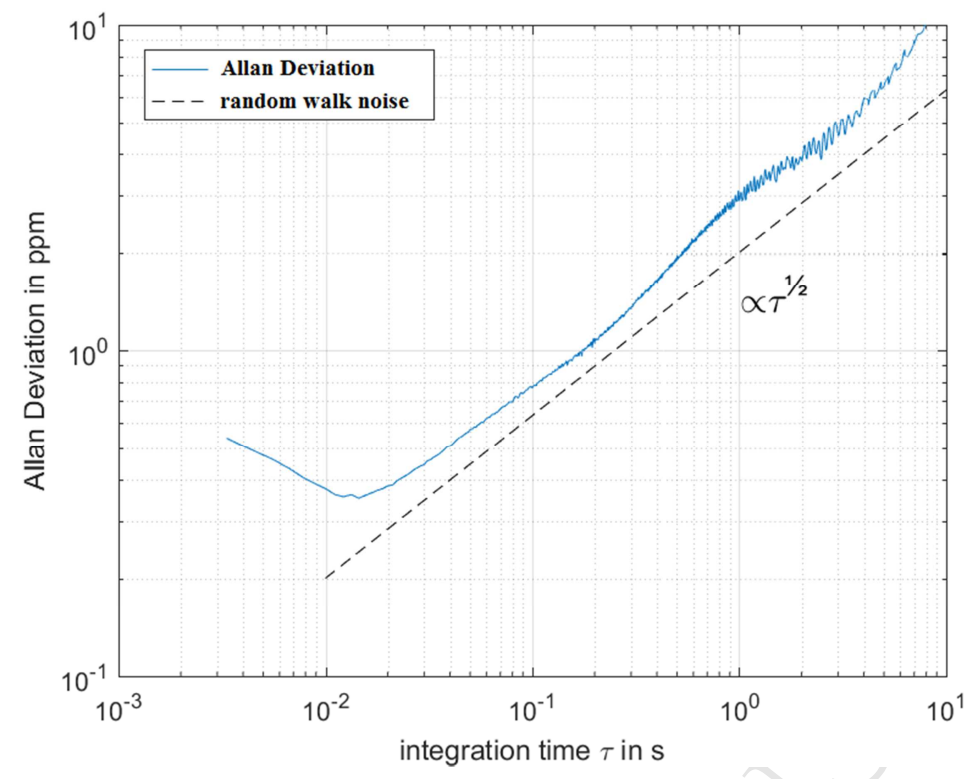

Figure 14: Allan Deviation of optimized SU-8/carbon string resonator $(\mathrm{L}=400 \mu \mathrm{m}$, width $=15 \mu \mathrm{m})$ in high vacuum.

\section{Conclusion}

In this work, we report the tailoring of stress in pyrolytic carbon thin films obtained through pyrolysis of both positive (AZ5214E) and negative (SU-8) photoresist by optimizing the pyrolysis process. Unpatterned carbon thin films and pyrolytic carbon string resonators were fabricated with different processing conditions and characterized using the bending plate method or interferometry respectively. The resonant behavior was used to calculate the tensile stress in the string resonators. Two major contribution affect the stress in pyrolytic carbon being i) the intrinsic stress due to material loss and shrinkage during the thermal processes and ii) the thermal stress due to mismatch of the CTE between carbon films and the underlying carrier substrate. For the pyrolysis temperature two regimes were identified: Below $800^{\circ} \mathrm{C}$ the residual stress was tensile and string resonators with excellent resonance behavior could be fabricated. Above $800^{\circ} \mathrm{C}$ residual stress was compressive due to large thermal stress which resulted in beam-like behavior of suspended structures or irreparable deformation due to stiction. Apparently, pyrolytic carbon probably has a lower CTE compared to Si. Faster ramping rate and shorter dwell time resulted in higher values of tensile stress, which is desirable for optimal performance of the carbon string resonators. The pyrolytic carbon string resonators showed the best performance when fabricated at $700^{\circ} \mathrm{C}$ pyrolysis temperature, $30^{\circ} \mathrm{C} / \mathrm{min}$ ramping rate and 10 minutes dwelling time. The optimized resonators having a length of $400 \mu \mathrm{m}$ 
displayed high resonance frequencies in the $300 \mathrm{kHz}$ range and $Q$ factors around $10^{4}$ in high vacuum. The resonance frequency did not change significantly during storage of the devices for several weeks, meaning that only minimal tensile stress was released during that period. However, the $Q$ factor decreased slightly during storage due to the absorption of oxygen or water from the environment. The resonance frequency and $Q$ factor can be recovered by re-heating the device before use. The performance of the optimized pyrolytic carbon strings was comparable with $\mathrm{SiN}$ resonators in term of resonance frequency, $Q$ factor and limit of detection. Compared to traditional MEMS materials, we believe that our pyrolytic carbon string resonators have the advantage of biocompatibility and conductivity. Furthermore, the properties of the pyrolytic carbon can be tailored for a specific experiment. Due to this, the optimized pyrolytic carbon resonators are very promising for various applications such as mass sensing or gas sensing.

\section{Acknowledgement}

The research is funded by the Danish National Research Foundation (DNRF122) and Villum Fonden (Grant No. 9301). Danish National Research Foundation's and the Villum Foundation's Center for Intelligent Drug delivery and Sensing Using Microcontainers and Nanomechanics.

\section{References}

[1] A. Boisen, S. Dohn, S. S. Keller, S. Schmid and M. Tenje, Cantilever-like micromechanical sensors, Rep. Prog. Phys, Vol.4, 2011.

[2] S. Schmid, K. D. Jensen, K. H. Nielsen, and A. Boisen, Damping mechanisms in high-Q micro and nanomechanical string, Physical Review B, Vol. 4, pp.165-307, 2011.

[3] S. Schmid and C. Hierold, Damping mechanisms of single-clamped and prestressed doubleclamped resonant polymer microbeams, Journal of Applied Physics, Vol. 104, pp. 093-516, 2008.

[4] J. S. Bunch, A. M. van der Zande, S. S. Verbridge, I. W. Frank, D. M. Tanenbaum, J. M. Parpia, H. G. Craighead, P. L. McEuen, Electromechanical resonators from graphene sheets, Science, Vol. 315, pp. 490-493, 2007.

[5] V. Sazonova, Y. Yaish, H. Ustunel, D. Roundy, T. A. Arias, P. L. McEuen, A tunable carbon nanotube electromechanical oscillator, Nature, vol. 431, pp. 284-287, 2004. 
[6] L. Sekaric, J. M. Parpia, H. G. Craighead, T. Feygelson, B. H. Houston, and J. E. Butler, Nanomechanical resonant structure in nanocrystalline diamond, Appl. Phys. Lett., Vol. 81, pp. 4455-4457, 2002.

[7] G. Cheng, Tzu. Chang, Q. Qin, H. Huang, and Y. Zhu, Mechanical properties of silicon carbide nanowires: effect of size-dependent defect density, Nano Letter, 2014 14(2), 754-758.

[8] Frank, I. W., Tanenbaum, D. M., Van Der Zande, A. M., \& McEuen, P. L., Mechanical properties of suspended graphene sheets, Journal of Vacuum Science and Technology B: Microelectronics and Nanometer Structures, 2007, 25(6), 2558-2561.

[9] R.S. Ruoff et al., Mechanical properties of carbon nanotubes, C. R. Physique 4 (2003)

[10] Kurek, Maksymilian; Larsen, Frederik K.; Larsen, Peter Emil; Schmid, Silvan; Boisen, Anja; Keller, Stephan Sylvest. Nanomechanical Pyrolytic Carbon Resonators: Novel Fabrication Method and Characterization of Mechnical Properties, Sensors, Vol. 16, No. 7, 2016, p. 1097.

[11] J. A. Lee, S. W. Lee, K.-C. Lee, S. I. Park, S. S. Lee, Fabrication and characterization of freestanding 3D carbon microstructures using multi-exposures and resist pyrolysis, J. Micromech. Microeng. Vol. 18, pp. 035012, 2008.

[12] S. Schmid, L. G. Villanueva, M. L. Roukes, Fundamentals of Nanomechanical Resonators, Springer Publishing, 2016.

[13] Q.P. Unterreithmeier, T. Faust, J.P. Kotthaus, Damping of Nanomechanical Resonators, Physical Review Letters 105 (2010) 027205.

[14] Larsen, ST, Argyraki, A, Amato, L, Tanzi, S, Keller, SS, Rozlosnik, N \& Taboryski, RJ, Pyrolyzed Photoresist Electrodes for Integration in Microfluidic Chips for Transmitter Detection from Biological Cells, ECS Electrochemistry Letters, vol 2, no. 5, pp. B5-B7, 2013.

[15] G. Stoney, The tension of metallic films deposited by electrolysis, Proc. R. Soc. London Ser. A, Vol. 82, (1909) p. 172.

[16] R.A. Jaccodine, W. A. Schlegel, Thin fillm stress measurement using Dektak Stylus Profilers, J. Appl. Phys., Vol. 37 (1966) p. 2429-34.

[17] R. Martinez-Duarte, P. Renaud, M.J. Madou, A novel approach to dielectrophoresis using carbon electrodes, Electrophoresis (2011), pp. 2385-2392. 
[18] S. Schmid, M. Kurek, A. Boisen, Towards airborne nanoparticle mass spectrometry with nanomechanical string resonators, Proc. SPIE 8725, Micro- and Nanotechnology Sensors, Systems, and Applications V, 872525 (4 June 2013)

[19] B.Y. Park, L. Taherabadi, C. Wang, J. Zoval, M.J. Madou, Electrical properties and shrinkage of carbonized photoresist films and the implications for carbon microelectromechanical systems devices in conductive media, J. Electrochem. Soc., 152 (2005), p. J136.

[20] S. Ranganathan, R. McCreery, S. M. Majji, and M. Madou, Photoresist-Derived Carbon for Microelectromechanical systems and Electrochemical Applications, Journal of the Electrochemical Society 2000 147: 277-282.

[21] A. Singh, J. Jayaram, M. Madou, S. Akbar, Pyrolysis of Negative Photoreists to Fabricate Carbon Structures for Microelectromechanical Systems and Electrochemical Applications, J. Electrochem. Soc. 149 (2002) E78.

[22] P R Shaina et al, Estimating the thermal expansion coefficient of graphene: the role of graphene-substrate interactions, J. Phys.: Condens. Matter 28 085301, 2016

[23] D. Yoon, Y W Son and H. Cheong, Negative Thermal Expansion Coefficient of Graphene Measured by Raman Spectroscopy, Nano Lett. 2011, 11(8), pp 3227-3231.

[24] Y.M. Hassan, C. Caviglia, S. Hermanth, D. M. A. Mackenzie, T. S. Alstrøm, D. H. Petersen, S. S. Keller, High temperature SU-8 pyrolysis for fabrication of carbon electrodes, Journal of Analytical and Applied Pyrolysis, Vol 125, 2017, pp 91-99

[25] S. Schmid, B. Malm and A. Boisen, Quality factor improvement of silicon nitride micro string resonators, 2011 IEEE 24th International Conference on Micro Electro Mechanical Systems, Cancun, 2011, pp. 481-484. 